Arqueología y Sociedad,

№ 23, 2011

\title{
NueVOS DATOS TENTATIVOS SOBRE LA MORFOLOGÍA LíticA DE la COLECCIÓN ARCATA DEL MUSEO DE ArQueOlogía Y ANTROPOlOGía, UNMSM
}

\author{
Juan Yataco Capcha ${ }^{i}$ \\ Edwin Ascencio Santiago ${ }^{i i}$ \\ Arnaldo Ramos Cuba ${ }^{i i i}$
}

\section{Resumen}

Las investigaciones sobre la morfotecnología y tipología lítica en la sierra sur del Perú, no han sido aún elaboradas, contando tan solo con descripciones superficiales. El presente trabajo expone los resultados de la aplicación del registro morfotecnológico efectuados a la colección lítica de Arcata. Los análisis nos han permitido, identificar puntas bifaciales, preformas de puntas, raspadores y otros artefactos de piedra. Estos han sido asociados desde el punto de vista morfotecnológico con otros yacimientos arqueológicos.

\section{Palabras clave}

Tecnología lítica, artefactos liticos, materia prima, colección lítica Arcata, Gerhard Schroeder.

\begin{abstract}
Lithic technology and typology research from south highland Perú has not been prepared yet, having only superficially descriptions. This paper show the results of morfotechnology register apply to the Arcata lithic collection. The analysis permitted to identify bifacial points, preforms of bifacial points, scrapers and other stone tools. The morfotechnology results are associated with other archaeological sites.
\end{abstract}

Keywords

Lithic technology, stone tools, raw material, Arcata lithic collection, Gerhard Schroeder.

Nota aclaratoria: Es necesario saber que el estudio del presente material lítico antrópico no presenta ningún tipo de asociación acerca de su registro de campo. Tan solo se tiene documentado el nombre del donador, la procedencia del sitio y los rótulos de las piezas líticas arqueológicas. Su estudio ha determinado un conjunto de cincuenta y cinco piezas arqueológicas modificadas, las cuales presentan una numeración consecutiva desde el L-0001 al L-0055.

i Licenciado en Arqueología, curador lítico del MAA-UNMSM.

Correo electrónico: capchajuan@gmail.com

ii Geólogo; egresado Facultad de Ingeniería Geológica, Minera, Metalúrgica y Geográfica de la UNMSM.

Correo electrónico: eddygeo_4@hotmail.com

iii Licenciado en Arqueología, egresado de la Universidad Católica de Santa Maria, Arequipa.

Correo electrónico: arcuba@hotmail.com 


\section{INTRODUCCIÓN}

Durante los trabajos de inventario que se viene efectuando en el Museo de Arqueología y Antropología del Museo de La Universidad Nacional Mayor de San Marcos, se encontró la colección de artefactos líticos arqueológicos que fueron recolectados a finales de los años cincuenta por el Dr. Gerhard Schroeder. El material arqueológico antrópico proviene de la región de Arcata, departamento de Arequipa, distrito de Cayarani. A pesar que el material arqueológico no cuenta con los registros científicos de campo, creemos que la investigación morfotecnológica lítica efectuada sobre esta colección ha permitido el ordenamiento del debitage-utillaje y la obtención de nuevos datos sobre la confección de los útiles.

\section{UBICACIÓN GEOGRÁFICA}

El yacimiento arqueológico de Arcata, se localiza en las inmediaciones de la mina del mismo nombre, en el actual departamento de Arequipa, provincia de Castilla, distrito de Cayarani, a una altura de $4800 \mathrm{msnm}$. No hemos podido localizar con precisión el sitio arqueológico y haciendo uso de las cartas geológicas hemos localizado la mina de Arcata. Sabiendo que el sitio arqueológico está en sus inmediaciones, hemos delimitado tentativamente un área de 4 $\mathrm{km}^{2}$ para nuestro estudio. La mina de Arcata se localiza con las coordenadas UTM 8'341,700 m S y 788,900 m E y el área tiene como coordenadas UTM los siguientes vértices:

Vértice A: 8’344,000 m S y 788,000 m E; Vértice B: 8’344,000 m S y 792,000 m E; Vértice C: 8’340,000 m S y 792,000 m E; Vértice D: 8’340,000 m S y 788,000 m E.

\section{ANTECEDENTES}

En 1957, año en que se publicó "Hallazgos de Artefactos de Piedra en el Perú y los Problemas del Poblamiento de América" Schroeder (1957), aborda de manera superficial y sin ningún tipo de información concreta los materiales líticos arqueológicos de Arcata.

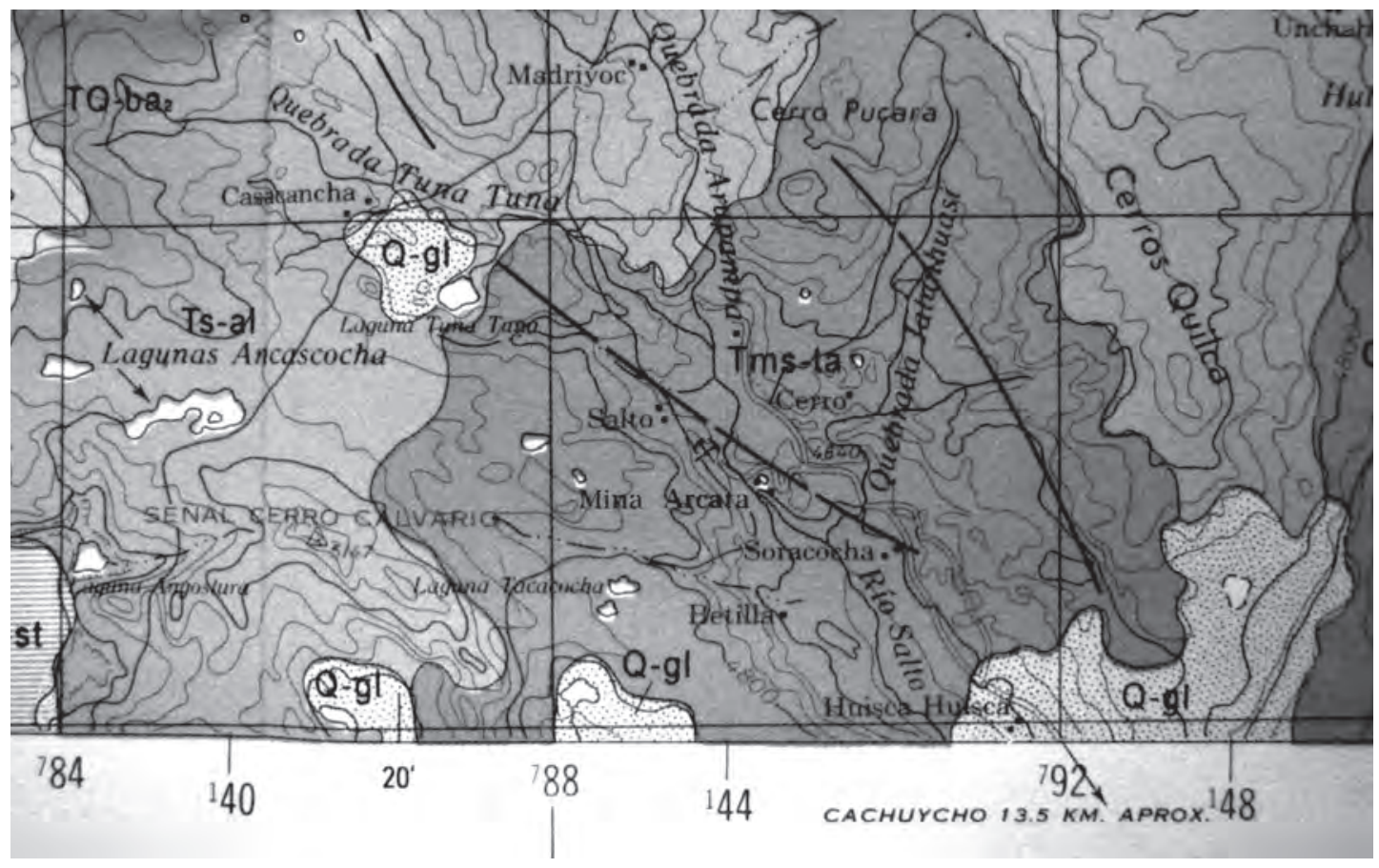

Figura 1: Mina de Arcata localizada en la parte central del mapa geológico (INGEMMET) escala 1:100,000 del cuadrángulo de Cayarani hoja (30-r) 
En efecto, Schroeder señala que: "...encontré en la región de Arcata una serie de estos "abrís" en una altura de 4,600 metros. Allí apareció una gran cantidad de artefactos, también puntas de flecha, raspadores y raederas" (Schroeder, 1957: 291). Además, en el citado artículo se exhiben los dibujos referenciales de cuarenta y dos piezas líticas de Arcata (Schroeder, Op. cit.), Si bien, estos son de difícil interpretación y de poca ayuda para su relación con los artefactos aquí en estudio, creemos que al menos unas diez piezas líticas pueden ser reconocibles sensu lato a partir de los dibujos de Schroeder.

Por otro lado, Máximo Neira (1966), expone brevemente sobre el yacimiento de Arcata, mencionando que gracias al estudio de la industria lítica efectuado por Schroeder, el yacimiento en estudio tiene aproximadamente entre seis mil a ocho mil años de antigüedad y que se asocia a la cultura Ayampitín II del Noroeste de Argentina (Neira 1966: 8).

Posteriormente, en 1970 Félix Alvarez, publica "Informe sobre los materiales de Arcata existentes en el Museo donados por el Dr. G. Schroeder" (Alvarez 1970). En este trabajo se señala que, el arqueólogo alemán Schroeder hizo el donativo al Museo de Arqueología y Etnología de la Universidad San Marcos y acompañado de un breve informe y/o relación de las piezas líticas que dejaba en manos del museo y que según Félix Alvarez fechaba "en Arequipa a 05-04-1958", sin embargo el manuscrito no ha sido hallado en el actual Museo de Arqueología y Antropología de la UNMSM (MAA-UNMSM). Si bien el trabajo científico exige la completa revisión bibliográfica, en honor a la verdad, los autores de la presente investigación no han podido consultar dicho manuscrito y nos basaremos en los datos de Félix Álvarez y somos conscientes de los errores a que nos puede llevar.

Refiriéndonos, nuevamente a los datos que expone Alvarez (1970), menciona que:

"El donativo consistía en 43 artefactos de piedra como ejemplares típicos de una cultura paleolítica del Perú y de 15 artefactos como material de enseñanza intuitiva en las clases de arqueología..."; luego dice que: "...la relación es breve y en ella describe 43 artefactos distinguiendo entre ellos núcleos, raspadores, raederas, lascas y puntas. Estos artefactos provienen de una excavación en trinchera que hizo en setiembre de 1956 en los abrigos rocosos de Arcata (PAr5-1), en Castilla, Dpto. de Arequipa" (Alvarez 1970: 46).

De las citas anteriores, es interesante notar que el autor proporcione las siglas (PAr-5-1), posiblemente del catálogo de sitios arqueológicos (Bonavia 1966: 55-71), pero la localización de este sitio por su nomenclatura a sido infructuosa debido a que no ha sido publicada.

Luego, el mismo autor, refiriéndose a los datos de campo de Schroeder y al parecer al manuscrito dejado en el MAA-UNMSM, expone que: "en ningún momento presenta asociaciones de artefactos líticos con otros elementos (huesos, cenizas, pieles, etc.)... Es decir, no presenta contextos, sino que simplemente presenta las piezas y las describe, y no todas" (cf. Álvarez 1970: 47). Félix Álvarez es categórico al mencionar que el Dr. Schroeder no describe todas las piezas donadas y que no hay datos estratigráficos y/o cronológicos de los materiales arqueológicos y concluye su informe con una descripción superficial de las piezas líticas antrópicas (Álvarez Op. cit.).

Sabiendo que una parte de esta colección se localiza en Arequipa (comunicación personal: Duccio Bonavia 2008), nos pusimos formalmente en contacto con la dirección del Museo José María Morante de la Universidad de San Agustín. En el documento enviado desde el MAAUNMSM (22.05.2011) expusimos que se trataban de 43 piezas líticas que el Dr. Schroeder donó a la Universidad Nacional de San Agustín (UNSA) y que de acuerdo a Neira, se tratan de: "un núcleo, dos hachas de mano, cinco raederas, quince raspadores de formas diversas, un cincel, dos agujas y diecisiete puntas de proyectil de diversas formas" (Neira et al. 1990: 9).

La respuesta por parte del Museo de la UNSA (Oficio №019-2011-MUNSA), ha sido satisfactoria pues autorizó a los investigadores el registro morfotecnológico de los materiales líticos arqueológicos de Arcata que tienen bajo custodia. Viendo la disposición del museo de la UNSA el Lic. Arnaldo Ramos Cuba, procedió a compa- 
rar las fichas de registro de campo depositadas en ambos museos, MAA-UNMSM y Museo-UNSA. En vista que el material dispuesto por el Museo de la UNSA no presenta rótulos y no indica de forma clara su asociación con la colección lítica del MAA-UNMSM y menos aún no hay indicios que indiquen que estos formen parte de los materiales donados por el Dr. Schroeder decidimos no intervenir en su registro. Por lo tanto, el presente informe versa sobre la colección lítica depositado en el MAA-UNMSM.

\section{OBJETIVOS Y MÉTODO DE LA INVESTIGACIÓN}

El primer problema de la colección radica que el material lítico de Arcata no ha sido definido morfotecnológicamente, y menos aún con la descripción métrica respectiva. Ya es sabido que, el registro cuidadoso de la masa y volumen de las piezas líticas procedentes de diferentes yacimientos arqueológicos, puede llevar a establecer medidas promedio para asociarlas con fases y/o estadios de talla. Esto permite mejorar sus definiciones y discernir los diferentes tipos de artefactos con el objetivo de una mejor comprensión de la tecnología lítica. Para la documentación morfotecnológica del material arqueológico, se ha empleado una ficha de registro la cual toma las características métricas de la masa y volumen del material antrópico (Pelegrin 1995: 26-32). En el presente trabajo pretendemos mostrar tentativamente los resultados de la aplicación de la ficha de registro que contiene las principales características métricas (p.g. porcentaje de córtex, ángulos de borde bifacial y de expulsión, etc.) aplicado sobre la colección de Arcata.

Antes de continuar, es necesario hacer unas aclaraciones. En primer lugar, somos conscientes de la limitación cuantitativa y cualitativa del material en estudio, como también, el de no disponer de datos estratigráficos y cronológicos. En segundo, nosotros hemos contabilizado cincuenta y cinco piezas líticas antrópicas modificadas, es decir, siete piezas más de las que describió Félix Álvarez y trece piezas también en demasía a partir de los dibujos que publicara el Dr. Schroeder (Schroeder 1957; Álvarez 1970:
47). Ante este problema, pensamos que el incremento de piezas, se deba al estado caótico de la conservación a las cuales han estado expuestas las colecciones líticas por más de veinte años. Otra posible explicación puede deberse a que el material lítico modificado de esta colección posiblemente nunca fue tratada en su totalidad por Félix Álvarez.

Por último, creemos que los resultados morfotecnológicos obtenidos aquí, podrían servir como base comparativa desde el punto de vista del registro métrico y tecnológico, aplicables para su asociación con otros estudios locales y que a futuro puedan pasar a formar parte de una base comparativa con piezas líticas procedentes de contextos estratigráficos que nos indiquen de mejor manera su temporalidad.

\section{ESTRATEGIA DE LA INVESTIGACIÓN}

Como primer paso, se realizó una revisión general del material lítico, luego se procedió a la identificación preliminar de las piezas. Seguidamente se elaboró el inventario partiendo de los apuntes anteriormente tomados, obteniéndose una primera división tipológica en cuatro grupos las cuales hemos denominado: lascas, utillaje, núcleos y piezas bifaciales. Una vez obtenido la separación de las piezas líticas por grupos, se continúo con el examen minucioso del material lítico con una lupa de 10X y 15X de aumento. Muy importante nos parece mencionar que, se ha documentado la existencia de preformas de bifaces y puntas terminadas. Al abordar el estudio de las lascas, se pudo constatar que estas también presentaban ciertas características particulares, la cual las hemos categorizado en LSPD, LSPB, laminillas y láminas. Estas dos últimas categorías fueron divididas por sus dimensiones métricas y morfológicas. En el caso de los útiles, también se ha visto permisible la elaboración una serie de tipos (e.g. raspadores, raederas, cuchillo, lascas modificadas a posteriori, etc).

A continuación en función a la colección, se crearon las fichas para preformas, lascas, núcleos y útiles. Estas fichas contemplan los rubros de mediciones, pesos, formas y tecnología. 
El resultado de dicho análisis se ha vertido a una base de datos en el formato Access y/o Excel, para facilitar el manejo de la información.

También hemos considerado significativo la identificación de la materia prima, lo cual nos mostrará una idea amplia del tipo recurrente en la selección del aprovisionamiento del material para talla.

\section{FicHA DE DOCUMENTACIÓN}

Las fichas de registro del material lítico aplicada sobre esta colección, presentan una serie de rubros, que en el sentido amplio se ha tomado de forma siguiente: características métricas, tecnológicas, peso, formas y observaciones. En general, todas las fichas contienen los mismos parámetros para la obtención de la información básica. En primer lugar en el encabezado, se puede observar el rótulo del tipo de ficha y nombre de la colección. En la parte inferior al rotulo, existe un cuadro para la determinación del material litico antrópico, luego medidas de longitud, peso, medidas angulares, descripciones de superficie, etc. Una vez concluido el llenado de todos los recuadros que contiene la ficha, se realiza la determinación diagnóstica de la pieza lítica (e.g. LSPD: lasca secundaria de percutor duro; LSPB: lasca secundaria de percutor blando; fragmento meso-distal de LSPD; bifaz, raspador, raedera, etc.).

Ha sido conveniente incluir a esta colección un numero secuencial por cada pieza lítica antrópica (e.g. L-0001, L-0002), para realizar así una localización más sencilla y obtener la cuantificación precisa de la colección.

También se ha introducido los recuadros relacionados a la obtención de los datos de análisis, insertando el rubro de materia prima, el cual comprende la observación sensu strictu sobre el tipo de roca. Se ha tenido exclusivo cuidado con la determinación de posibles contenidos de material orgánico y adherencias de posible hollín en la colección, ya que pueden servirnos para la realización de futuros análisis.

\section{MATERIAL Lítico}

\section{Tipología}

Con respecto a la elaboración tipológica del material lítico en especial para el área Sur andina, sabemos que esta tiene serios vacíos. En vista de la no existencia de parámetros claros para su interpretación, diversos autores han hecho el uso de diferentes denominaciones. Además se han efectuado una serie de intentos tipológicos por realizar secuencias cronológicas basándose en la morfología de las puntas de proyectil procedentes de distintos sitios arqueológicos con o sin contextos estratigráficos (cf. Ravines 1972: 133-184; 2008: 39-72; Klink et al. 2005: 25-54). Si bien este tipo de secuencias pueden ser útiles para identificar marcadores cronológicos en el área Sur andina en asociación con contextos arqueológicos seguros, nos mostramos en desacuerdo con abordar la tecnología lítica incidiendo tan solo por las formas de los artefactos. Este tipo de secuencias resulta ser un problema debido a que las formas de las puntas de proyectil y/o otros artefactos son recurrentes a lo largo de distintos periodos de tiempo.

Viendo que el material de la colección de Arcata presenta algunos útiles especializados, hemos creído posible utilizar algunos de los tipos definidos en la arqueología europea (Bordes 1981; Merino 1994; Sonneville-Bordes \& Brezillon 1954; Inizan et al. 1995), además, hemos hecho empleo de tres tipologías científicas serias propuestas para el área andina peruana (Bonavia 1982, 1992; Chauchat 1972, 1982; Lavallée et al. 1995).

Es necesario dejar en claro, que pretendemos aquí esbozar la elaboración tipológica a partir del conjunto lítico estudiado, empero, somos categóricos al aclarar que para el efecto de la definición tipológica, no tomamos en cuenta temporalidad alguna y más bien hacemos uso de esta, para el ordenamiento del material lítico antrópico desde el punto morfotecnológico.

El orden tipológico ensayado aquí es como sigue (vide, Cuadro1 y Diagrama 1): 


\begin{tabular}{|c|c|c|}
\hline \multicolumn{3}{|c|}{ Tipología lítica de Arcata } \\
\hline Tipología & Cantidad & Porcentaje \\
\hline \multicolumn{3}{|l|}{ A.01. Puntas } \\
\hline A.01.1. Fragmento apical de punta bifacial & 1 & $1.81 \%$ \\
\hline A.01.2. Punta bifacial foliácea ancha de base cóncava & 1 & $1.81 \%$ \\
\hline A.01.3. Punta bifacial foliácea de base recta & 1 & $1.81 \%$ \\
\hline A.01.4. Punta bifacial romboidal de base recta & 2 & $3.63 \%$ \\
\hline A.01.5. Punta bifacial triangular de base cóncava & 2 & $3.63 \%$ \\
\hline A.01.6. Punta bifacial lanceolada de base cóncava & 1 & $1.81 \%$ \\
\hline \multicolumn{3}{|l|}{ A.02. Preformas de bifaz y/o puntas } \\
\hline A.02.1. Preforma de bifaz & 1 & $1.81 \%$ \\
\hline A.02.2. Preforma de punta foliácea de base recta & 1 & $1.81 \%$ \\
\hline A.02.3. Preforma de punta romboidal de base cóncava & 2 & $3.63 \%$ \\
\hline \multicolumn{3}{|l|}{ Tipología unifaciales } \\
\hline \multicolumn{3}{|l|}{ B. ÚTILES ORDINARIOS } \\
\hline \multicolumn{3}{|l|}{ B.01. Cuchillo } \\
\hline B.01.1. Cuchillo atípico & 1 & $1.81 \%$ \\
\hline \multicolumn{3}{|l|}{ B.02. Útiles modificados. } \\
\hline B.02.1. UM/LaminillaPB modificada & 2 & $3.63 \%$ \\
\hline B.02.2. UM/LaminillaPD modificada & 5 & $9.09 \%$ \\
\hline \multicolumn{3}{|l|}{ B.03. Útil a posteriori } \\
\hline B.03.1. LSPD modificada a posteriori & 6 & $10.90 \%$ \\
\hline \multicolumn{3}{|l|}{ B.04. Raedera } \\
\hline B.04.1. Raedera doble biconvexa sobre LSPD & 2 & $3.63 \%$ \\
\hline B.04.3. Raedera convergente convexa sobre LSPB & 1 & $1.81 \%$ \\
\hline \multicolumn{3}{|l|}{ B.05. Raspador } \\
\hline B.05.1. Raspador atípico & 1 & $1.81 \%$ \\
\hline B.05.2. Raspador circular & 2 & $3.63 \%$ \\
\hline B.05.3. Raspador sobre Lasca & 12 & $21.81 \%$ \\
\hline \multicolumn{3}{|l|}{ B.06. Unifaz } \\
\hline B.06.1. Unifaz sobre LSPD & 3 & $5.45 \%$ \\
\hline \multicolumn{3}{|l|}{ C. Núcleo } \\
\hline C.01. Blank de núcleo & 1 & $1.81 \%$ \\
\hline \multicolumn{3}{|l|}{ D. Desechos de talla } \\
\hline D.01. LSPB & 1 & $1.81 \%$ \\
\hline D.02. LSPD & 1 & $1.81 \%$ \\
\hline D.03. LaminillaPD & 1 & $1.81 \%$ \\
\hline D.04. Micro laminillaPB & 4 & $7.27 \%$ \\
\hline Total Piezas & 55 & $99.83 \%$ \\
\hline
\end{tabular}

Cuadro 1: Tipología lítica de Arcata, con cantidades y porcentajes 


\section{Distribución porcentual del Utillaje-Debitage}

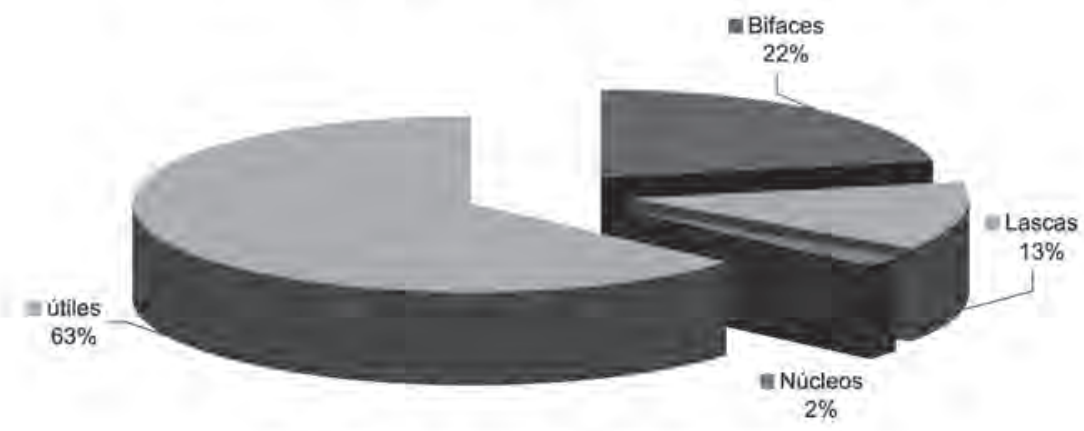

Bifaces = Lascas - Núcleos ne útiles

Diagrama 1.- Distribución Porcentual Total del Utillaje-Debitage, Arcata

DeFINICIÓN TIPOLÓGICA

\section{A.01. Puntas}

Al menos, las puntas de Arcata concuerdan dentro del marco de las tipologías de los Andes Centrales (cf. Lavallée et al. 1995: 127-129; Chauchat 1972: 126-128, 131). Se tiene a continuación los siguientes tipos:

\section{A.01.1. Fragmento apical de punta bifacial \\ Hemos creído conveniente aclarar el si- guiente tipo, pues se trata de un solo frag- mento apical de punta bifacial, por tal mo- tivo, no hemos podido reconstruir su forma. Sin embargo, podemos decir que este frag- mento de punta se encuentra tallada a pre- sión. Posiblemente se trate de las puntas del tipo A.01.6.}

\section{A.01.2. Punta bifacial foliácea ancha de base cóncava \\ Punta bifacial foliácea tallada generalmente a presión, mostrando típicamente una for- ma foliácea de base cóncava. Sus bordes son frecuentemente rectos o algo convexos.}

\section{A.01.3. Punta bifacial foliácea de base recta} Punta bifacial tallada generalmente a presión, mostrando una forma típicamente foliácea de base recta. Sus bordes son ligeramente convexos.

\begin{abstract}
A.01.4. Punta bifacial romboidal de base recta

Punta bifacial tallada generalmente a percusión blanda y/o presión, completamente simétrica. Muestra una forma típica romboidal de base recta. Sus bordes son ligeramente rectos convexos.
\end{abstract}

\section{A.01.5. Punta bifacial triangular de base cóncava}

Punta bifacial tallada a presión y/o percusión blanda, configurando una silueta de forma homogénea triangular de bordes rectos y base cóncava.

\section{A.01.6. Punta bifacial lanceolada con base cóncava \\ Punta bifacial generalmente tallada a pre- sión, de forma lanceolada y de base cón- cava. Su sección es cóncava convexa y de bordes laterales convexos.}

\section{A.02. Preformas de bifaz y/o puntas}

La lista tipológica de las preformas de piezas bifaciales es la siguiente:

\section{A.02.1. Preforma de bifaz}

Pieza reducida a percutor duro, presenta una forma rectangular, reducido por talla alterna, con aristas ligeramente pronunciadas y de simetría irregular, lo cual prueba que esta pieza se encuentra aún en estado de manufactura. 
Al no haber detectado fases de reducción en la cadena operativa, es difícil definir si se trata de una pieza terminada.

\section{A.02.2. Preforma de punta foliácea de base recta}

Se trata de una punta en proceso de reducción. Proviene de una LSPD, tallada a percusión dura y, eventualmente, a percusión blanda. La forma foliácea, perfil cóncavo convexo y sección triangular irregular con ligeras aristas, nos indica que aún esta en proceso de reducción. Es una pre-punta tallada a percusión bifacial.

\section{A.02.3. Preforma de punta romboidal de base cóncava \\ Punta bifacial, tallada generalmente a pre- sión, mostrando una forma típicamente romboidal de base cóncava, bastante bien configurada. Su vista en sección de forma triangular nos indica que aún esta en proce- so de reducción.}

\section{ÚtILES ORDINARIOS}

\section{Tipología de unifaciales}

\section{B.01.1. Cuchillo atípico}

Se trata de un útil sobre una lasca alargada, uno de cuyos bordes está delineado por un corte abrupto, pero que puede mostrar huellas de utilización. El borde opuesto se presenta modificado con un retoque unifacial agudo, según los casos (cf. Merino 1994: 67).

\section{B.02 Útiles modificados (UM)}

Se trata de siete lascas y otros restos de debitage que muestran retoque intencional, no fortuito. Los bordes modificados se muestran bastante regulares. Las modificaciones supuestamente intencionales parecen haber sido elaboradas en la mayoría de los casos por posible percusión blanda y dura. Es difícil sugerir una función a estas piezas. Es posible sugerir, a juzgar por sus reducidas dimensiones y ángulos de bordes activos agudos, que han sido usadas para el procesamiento de materiales blandos. De acuerdo a los soportes donde ocurren, se las ha subdividido en los dos subtipos siguientes:

\section{B.02.1. UM/LaminillaPB modificada}

Se trata de dos laminillas, generalmente obtenidas por percutor blando, se observa en uno de sus bordes desprendimientos regulares, usualmente unifaciales y agudos, que pueden proceder de retoque de posición directa intencional.

\section{B.02.2. UM/LaminillaPD modificada}

Se tiene registrado cinco laminillas, generalmente producidas a percutor duro. Contiene en uno de sus bordes desprendimientos regulares, usualmente unifaciales, que pueden proceder de retoque intencional.

\section{B.03. Útil a posteriori (UP)}

Se trata de piezas líticas sobre lascas que presentan pequeños retoques irregulares discontinuos tanto unifacial como bifacial o alternante, localizándose generalmente en el extremo distal y en los bordes laterales de las lascas; estos pueden ser originados debido a producto antrópico, natural, o posiblemente por uso (Bordes 1981: 67).

\section{B.03.1. LSPD modificada a posteriori}

Se tiene registrados seis lascas secundarias a percusión dura, que posee en uno o dos de sus bordes, incluido en extremo distal, desprendimientos a posteriori.

\section{B.04. Raederas}

Definidas como lascas que presentan retoque continuo directo sobre un borde. En esta serie lítica investigada son raederas dobles biconvexas y convergente convexa.

\section{B.04.1. Raedera doble biconvexa sobre LSPD}

Se trata de dos LSPD modificadas por retoques agudos y semiabruptos sobre los dos bordes laterales opuestos al eje de la lasca. Sus retoques presentan una delineación biconvexa.

\section{B.04.2. Raedera convergente convexa sobre LSPB}

Tenemos la presencia de una lasca a percusión blanda, presentando simultáneamente retoques agudos a semiabruptos sobre ambos bordes que convergen en un punto central. La pieza posee retoque de delineación convexa y morfología escamosa. 


\section{B.05. Raspadores}

Láminas o lascas que muestran en una o dos extremidades un retoque continuo no abrupto que determina un frente mas o menos redondeado o parabólico, rara vez rectilíneo, y más raro aún cóncavo (Merino 1994: 67; Piel-Desruisseaux 1989: 92). Esta presenta variantes definidas por la tipología clásica, que a continuación se detalla:

\section{B.05.1. Raspador atípico}

Raspador poco frecuente en el material estudiado. Los ejes están distorsionados y la forma es bastante irregular, tendiente siempre a la convexidad irregular. La sección típica es plano convexa y se localiza el borde lateral izquierdo al eje de la lasca.

\section{B.05.2. Raspador circular}

Se trata de dos raspadores con retoques periféricos que fluctúa con un ángulo entre semiabruto a abrupto. Los retoques se localizan sobre toda la periferia o circunferencia de la pieza.

\section{B.05.3. Raspador sobre lasca}

Es un tipo de raspador elaborado sobre LSPD y LSPB. Su ángulo de borde activo se extiende a veces a todo el perímetro, salvo el talón que siempre aparece conservado (Merino 1994: 100).

\section{B.06. Unifaz}

En nuestra tipología se ha podido notar que las piezas modificadas unifacialmente están confeccionadas sobre LSPD. A continuación detallamos:

\section{B.06.1. Unifaz sobre LSPD}

Se han reconocido tres piezas sobre LSPD talladas unifacialmente que, presentan formas generalmente triangular, rectangular y lanceolada. Los retoques suelen estar hechos por medio de percusión dura y eventualmente por presión. Las formas laterales rectaconvexas posiblemente han sido usadas en función de raspado ó afines, asumiendo los ángulos de borde activo semiabruptos a abruptos como suele suceder con los unifaces. Empero, desde el punto de vista de la morfología, estos son atípicos.

\section{Núcleo}

Lo conforma solo el $1.81 \%$ de todo el material y debido a su gran importancia se ha creído necesario darle una descripción detallada. Los núcleos son fuentes potenciales de información, en combinación con las lascas, é incluso sin ellas, durante las tareas efectuadas en el proceso de reducción lítica, i.e. dentro de la secuencia de la cadena operativa. Para ello solo hemos contado con la presencia del siguiente tipo:

\section{C.01. Blank de núcleo}

Se trata de una sola pieza de obsidiana en bruto, de forma trapezoidal ó cuadrangular, generalmente con índices de vitrificación (obsidiana). Solo se ha observado la presencia de un negativo que indica el posible intento de extracción de soporte sobre ella. La presencia de útiles y desechos de talla del mismo tipo de roca, puede implicar la posibilidad de haber sido importadas a los sitios en función de ser desbastadas. Su estado sin modificación puede deberse por algún olvido, ó sencillamente el blank no reunió las características necesarias para ser desbastada.

\section{Desechos de talla}

Los desechos de talla lo conforman un 13\%, de todo el material documentado. A partir del análisis, hemos creado una lista de cuatro grupos. Dichos grupos han sido definidos a partir de la tecnología empleada para su obtención. Así hemos obtenido una lasca secundaria a percusión blanda (D.01.1. LSPB), una lasca secundaria a percusión dura (D.02. LSPD), una laminilla a percusión dura (D.03. LaminillaPD) y cuatro microlaminillas a percusión blanda (D.04. MicroLaminillaPB).

Para la diferencia entre laminilla y microlaminillas, se siguió el criterio de longitud doble del ancho. Posteriormente, luego del análisis se ha hecho distinción, puesto que las microlaminillas son mas pequeñas en comparación con las laminillas usuales (cf. Merino, 1994: 261, 262). Al final, hemos decidido usar solo los dos términos antes descritos: en el caso de las microlaminillas, estas son lascas alargadas cuyas longitudes oscilan entre $20 \mathrm{~mm}$ y $40 \mathrm{~mm}$. Las laminillas también son 
lascas alargadas cuyas longitudes fluctúan entre $40 \mathrm{~mm}$ a $70 \mathrm{~mm}$. Debido a su importancia como indicador potencial de trabajo de reducción bifacial, han sido cuidadosamente registradas.

\section{Análisis Petrográfico}

El análisis petrográfico de las cincuenta y cinco piezas líticas que hemos registrado para esta colección han sido examinadas en su totalidad. Se ha tenido como resultado distintas variedades de sílice $\left(\mathrm{SiO}_{2}\right)$; contando entre ellas variedades amorfas como la obsidiana y por otro lado las variedades de sílice denominadas microcristalinas e.g. jaspe, calcedonia, sílex y chert. Entre estas dos categorías hemos contado con la mayor predominancia del material denominado como obsidiana en un $63.5 \%$, seguido del jaspe $25.4 \%$, calcedonia $7.3 \%$, chert $1.8 \%$ y silex en un $1.8 \%$ (Vide, cuadro 2 ).

\begin{tabular}{|c|c|c|}
\hline Materia prima & № de piezas & Porcentaje \\
\hline Obsidiana & 35 & $63.5 \%$ \\
\hline Jaspe & 14 & $25.4 \%$ \\
\hline Calcedonia & 4 & $7.3 \%$ \\
\hline Chert & 1 & $1.8 \%$ \\
\hline Sílex & 1 & $1.8 \%$ \\
\hline Total & 55 & $100.0 \%$ \\
\hline
\end{tabular}

Cuadro 2: Distribución porcentual de la materia prima

\section{Obsidiana}

Las piezas líticas antrópicas de obsidiana suman un total de treinta y cinco, estas presentan diversas tonalidades, debido al mayor o menor contenido de fierro (Fe) metal de transición; magnesio $(\mathrm{Mg})$ metal alcalino terreo y óxidos (e.g. hematina). Las tonalidades de las obsidianas que varían desde el negro al gris se deben al contenido de los dos primeros metales $(\mathrm{Mg}$ y $\mathrm{Fe}$ ) y la tonalidad que varía del marrón al marrón rojizo se debe al contenido de óxidos. La tonalidad verdosa se ha detectado en baja recurrencia

1 El análisis petrográfico se ha llevado a cabo con la ayuda del geólogo Edwin Ascencio de la Facultad de Ingeniería Geológica de la Universidad Nacional Mayor de San Marcos. y se han reconocido obsidianas que presentan una textura del color en franjas, mostrándose en algunos casos mezcla entre las tonalidades. Un caso ejemplar a esta mezcla de tonalidades es la pieza con número de inventario L-0041, lo cual puede indicar elucubrativamente que la obsidiana provenga de un único afloramiento.

Por otro lado, refiriéndonos a la fractura de este material vítreo, ya es sabido de su alta tenacidad, fragilidad y buena materia prima para la talla, siendo su fractura del tipo concoidea y alcanzando una dureza en la escala de Mohs que oscila entre 6-6,5.

Finalmente, en el cuadro № 3 exponemos las treinta y cinco piezas líticas arqueológicas, su determinación petrográfica, variaciones de color y dureza.

\section{Calcedonia}

Solo se ha detectado cuatro piezas líticas modificadas sobre calcedonia, este tipo de materia prima al igual que la obsidiana presenta un fractura concoidal (Cuadro 4). Sus tonalidades varían de un amarillo a naranja y marrón a negro rojizo. Al menos las piezas L-0029 y L-0030 están dentro de esta denominación debido a su pureza ya que se trataría el primero de un cuarzo lechoso y el segundo de un cuarzo del tipo coloidal. Las piezas L-0039 y L-0053, presentan combinaciones de cuarzo y jaspe. Su dureza en la escala de Mohs es de un 6-6,5.

\section{Chert}

Solo se tiene identificado una pieza arqueológica sobre chert. Se trata en realidad de una variedad microcristalina de cuarzo, su color es negro grisáceo y su dureza es de 6-6,5 en la escala de Mohs (Cuadro 5).

\section{Silex}

Formado por soluciones cargadas de sílice, solo se ha tenido la presencia de una sola pieza lítica. Su color varía de un tono gris a un ligero tono azul (Cuadro 6). 


\begin{tabular}{|c|c|c|c|}
\hline \multicolumn{4}{|c|}{ ANÁLISIS PETROGRÁFICO DEL MATERIAL LÍTICO ARQUEOLÓGICO (ARCATA) } \\
\hline $\begin{array}{l}\text { Código } \\
\text { Inventario }\end{array}$ & Materia prima & Color & Dureza (Escala de Mohs) \\
\hline L-0001 & Obsidiana & gris negro & $6-6,5$ \\
\hline L-0002 & Obsidiana & $\begin{array}{l}\text { negro y marrón rojizo en franjas y/o de } \\
\text { forma dendrítica }\end{array}$ & $6-6,5$ \\
\hline L-0003 & Obsidiana & gris negro e incoloro & $6-6,5$ \\
\hline L-0004 & Obsidiana & gris negro & $6-6,5$ \\
\hline L-0005 & Obsidiana & gris negro & $6-6,5$ \\
\hline L-0006 & Obsidiana & incoloro (ligero gris) & $6-6,5$ \\
\hline L-0007 & Obsidiana & negro y marrón rojizo & $6-6,5$ \\
\hline L-0008 & Obsidiana & gris negro & $6-6,5$ \\
\hline L-0009 & Obsidiana & negro grisáceo & $6-6,5$ \\
\hline L-0010 & Obsidiana & gris negro & $6-6,5$ \\
\hline L-0011 & Obsidiana & gris negro & $6-6,5$ \\
\hline L-0014 & Obsidiana & gris negro & $6-6,5$ \\
\hline L-0015 & Obsidiana & gris negro e incoloro & $6-6,5$ \\
\hline L-0016 & Obsidiana & gris negro, incoloro & $6-6,5$ \\
\hline L-0017 & Obsidiana & incoloro (ligero gris) & $6-6,5$ \\
\hline L-0018 & Obsidiana & $\begin{array}{l}\text { marrón rojizo y diversas tonalidades } \\
\text { de este }\end{array}$ & $6-6,5$ \\
\hline L-0019 & Obsidiana & incoloro (ligero gris) & $6-6,5$ \\
\hline L-0020 & Obsidiana & incoloro (ligero gris) & $6-6,5$ \\
\hline L-0022 & Obsidiana & gris negro/verde olivino & $6-6,5$ \\
\hline L-0023 & Obsidiana & incoloro (ligero gris) & $6-6,5$ \\
\hline L-0024 & Obsidiana & incoloro, gris negro y marrón rojizo & $6-6,5$ \\
\hline L-0025 & Obsidiana & incoloro (ligero gris) & $6-6,5$ \\
\hline L-0027 & Obsidiana & incoloro (ligero gris) & $6-6,5$ \\
\hline L-0031 & Obsidiana & incoloro (franjas blancas) & $6-6,5$ \\
\hline L-0032 & Obsidiana & incoloro (ligero gris) & $6-6,5$ \\
\hline L-0033 & Obsidiana & incoloro (ligero gris) & $6-6,5$ \\
\hline L-0034 & Obsidiana & gris negro & $6-6,5$ \\
\hline L-0035 & Obsidiana & gris negro & $6-6,5$ \\
\hline L-0037 & Obsidiana & gris negro & $6-6,5$ \\
\hline L-0040 & Obsidiana & incoloro, gris & $6-6,5$ \\
\hline L-0041 & Obsidiana & incoloro (ligero gris) & $6-6,5$ \\
\hline L-0042 & Obsidiana & incoloro (ligero gris) & $6-6,5$ \\
\hline L-0043 & Obsidiana & incoloro (ligero gris) & $6-6,5$ \\
\hline L-0052 & Obsidiana & negro y negro verdosa & $6-6,5$ \\
\hline L-0055 & Obsidiana & negro grisáceo & $6-6,5$ \\
\hline
\end{tabular}

Cuadro 3: Piezas arqueológicas modificadas en obsidiana (color y dureza) 


\begin{tabular}{|c|c|c|c|}
\hline \multicolumn{3}{|c|}{ ANÁLISIS PETROGRÁFICO DEL MATERIAL LÍTICO ARQUEOLÓGICO (ARCATA) } \\
\hline $\begin{array}{c}\text { Código } \\
\text { Inventario }\end{array}$ & Materia prima & Color & $\begin{array}{c}\text { Dureza (Escala de } \\
\text { Mohs) }\end{array}$ \\
\hline L-0029 & Calcedonia & blanco (tonalidad azul violáceo) & $6-6,5$ \\
\hline L-0030 & Calcedonia & negro grisáceo & $6-6,5$ \\
\hline L-0039 & Calcedonia & amarillo naranja y marrón rojizo & $6-6,5$ \\
\hline L-0053 & Calcedonia & naranja amarillento y tonalidades & $6-6,5$ \\
\hline
\end{tabular}

Cuadro 4: Piezas arqueológicas modificadas en calcedonia (color y dureza)

\begin{tabular}{|c|c|c|c|}
\hline \multicolumn{3}{|c|}{ ANÁLISIS PETROGRÁFICO DEL MATERIAL LÍTICO ARQUEOLÓGICO (ARCATA) } \\
\hline $\begin{array}{c}\text { Código } \\
\text { Inventario }\end{array}$ & Materia prima & Color & $\begin{array}{c}\text { Dureza (Escala de } \\
\text { Mohs) }\end{array}$ \\
\hline L-0012 & Chert & negro grisáceo & $6-6,5$ \\
\hline
\end{tabular}

Cuadro 5: Pieza arqueológica modificada sobre Chert (color y dureza)

\begin{tabular}{|c|c|c|c|}
\hline \multicolumn{3}{|c|}{ ANÁLISIS PETROGRÁFICO DEL MATERIAL LÍTICO ARQUEOLÓGICO (ARCATA) } \\
\hline $\begin{array}{c}\text { Código } \\
\text { Inventario }\end{array}$ & Materia prima & Color & $\begin{array}{c}\text { Dureza (Escala de } \\
\text { Mohs) }\end{array}$ \\
\hline L-0054 & Sílex & gris con ligero tono azul & $6-6,5$ \\
\hline
\end{tabular}

Cuadro 6: Pieza arqueológica modificada sobre silex (color y dureza)

Jaspe

Finalmente catorce piezas conforman los jaspes, su fractura ha sido determinada como subconcoidea, presentando una dureza de 6-6,5 en la escala de Mohs. Sus tonalidades se aprecian desde beige al marrón rojizo (Cuadro 7).

\section{RESUlTADOS DEL ANÁLISIS}

El registró morfotecnológico de las piezas líticas antrópicas nos ha arrojado nuevos datos sobre esta pequeña colección. Nosotros pasaremos ha describir los datos obtenidos a partir de nuestro análisis lítico siguiendo el orden de la tipología lítica propuesta para esta colección.

\section{A.01. Puntas}

Tipo (A.01.1) fragmento apical de punta bifacial
Se trata de un fragmento apical de punta bifacial, tiene el número de inventario L-0008, tallado sobre obsidiana. Presenta una pátina brillosa y el blank ha podido ser una LSPD alargada, su longitud es de $21 \mathrm{~mm}$, ancho de $18 \mathrm{~mm}$ y espesor de $6 \mathrm{~mm}$. Su máximo ancho y espesor se localiza en la parte mesial de la pieza. El peso es de 1.16 gr, su ángulo de borde activo es de $45^{\circ}-50^{\circ}$. Su silueta es triangular, vista de perfil y sección tiene una silueta plano convexa, siendo en blank de una lasca. La tecnología empleada en su superficie superior e inferior ha sido la percusión blanda o presión. No hay presencia de córtex. Con respecto a los retoques, su delineación es recta, extensión larga, inclinación entre aguda a semiabrupta, localizándose en toda la periferia de la pieza. La morfología es irregular y escamosa, de posición bifacial y distribución continua. Se ha podido detectar una fractura transversal debido a causas tecnológicas. A juzgar por sus características se trata de una pieza fracturada al parecer en la última fase de talla. 


\begin{tabular}{|c|c|c|c|}
\hline \multicolumn{2}{|c|}{ ANÁLISIS PETROGRÁFICO DEL MATERIAL LÍTICO ARQUEOLÓGICO (ARCATA) } \\
\hline $\begin{array}{c}\text { Código } \\
\text { Inventario }\end{array}$ & Materia prima & Color & $\begin{array}{c}\text { Dureza (Escala de } \\
\text { Mohs) }\end{array}$ \\
\hline L-0013 & Jaspe & beige y marrón rojizo & $6-6,5$ \\
\hline L-0021 & Jaspe & Beige & $6-6,5$ \\
\hline L-0026 & Jaspe & marrón rojizo & $6-6,5$ \\
\hline L-0028 & Jaspe & marrón rojizo & $6-6,5$ \\
\hline L-0036 & Jaspe & $\begin{array}{c}\text { marrón rojizo y marrón oscuro } \\
\text { (ligero gris) }\end{array}$ & $6-6,5$ \\
\hline L-0038 & Jaspe & marrón rojizo & $6-6,5$ \\
\hline L-0044 & Jaspe & $\begin{array}{c}\text { marrón rojiza, amarillo naranja } \\
\text { (intercrecido) }\end{array}$ & $6-6,5$ \\
\hline L-0045 & Jaspe & amarillo naranja & $6-6,5$ \\
\hline L-0046 & Jaspe & marrón oscuro & $6-6,5$ \\
\hline L-0047 & Jaspe & $\begin{array}{c}\text { amarillo naranja y marrón rojizo } \\
\text { (intercrecido) }\end{array}$ & $6-6,5$ \\
\hline L-0048 & Jaspe & $\begin{array}{c}\text { marrón rojizo y tonalidades más } \\
\text { oscuras }\end{array}$ & $6-6,5$ \\
\hline L-0049 & Jaspe & marrón rojizo oscuro & $6-6,5$ \\
\hline L-0050 & Jaspe & $\begin{array}{c}\text { amarillo naranja y marrón rojizo } \\
\text { (intercrecido) }\end{array}$ & $6-6,5$ \\
\hline L-0051 & Jaspe & marrón rojizo & $6-6,5$ \\
\hline
\end{tabular}

Cuadro 7: Piezas arqueológicas modificadas en Jaspe (color y dureza)

\section{Tipo (A.01.2) Punta bifacial foliácea} ancha de base cóncava

Este tipo esta determinado por una punta bifacial foliácea de base cóncava L-0055, tallada sobre obsidiana. Tiene una longitud de $20 \mathrm{~mm}$, ancho de $16 \mathrm{~mm}$ y espesor de $5 \mathrm{~mm}$. El máximo ancho se localiza sobre la parte basal de la pieza y su máximo espesor sobre la parte mesial. Su peso es de 1.23 gr. Su ángulo de borde activo bifacial oscila entre $40^{\circ}$ y $45^{\circ}$ siendo su silueta de forma triangular, su vista de perfil de forma cóncava convexa y de sección biconvexa. La tecnología empleada en la superficie superior e inferior ha sido la presión o percusión blanda. La pieza esta muy bien configurada, presentando una simetría perfecta sin aristas. No hay presencia de córtex. $\mathrm{Su}$ retoque presenta una delineación convexa, de extensión corta, inclinación aguda, localizán- dose en toda la periferia de la punta, la morfología de los retoques es paralela irregular de posición bifacial y distribución continua. La base de la punta se ha elaborado al parecer a partir de una muesca a presión de forma cóncava.

\section{Tipo (A.01.3) Punta bifacial foliácea de base recta}

En realidad es un fragmento meso basal de punta bifacial foliácea de base recta L-0036. Esta modificada sobre un jaspe con pátina brillosa, su longitud es de $38 \mathrm{~mm}$, ancho de $28 \mathrm{~mm}$ y espesor de $7 \mathrm{~mm}$. El máximo ancho y espesor se ubica en la parte mesial del artefacto. Presenta un peso de 5.52 gr. El ángulo de borde bifacial oscila entre $30^{\circ}$ y $45^{\circ}$, siendo su silueta de forma trapezoidal, perfil convexo y sección biconvexa. La tecnología empleada en su superficie superior e inferior ha sido la percusión blanda sin presen- 
cia de córtex. En su parte mesial se ha observado una fractura transversal por causas tecnológicas, quizá realizada al momento final de la talla.

Finalmente, sus retoques han presentado una delineación convexa, extensión larga, inclinación aguda, localizada en el borde periférico del artefacto, estas presentan una morfología paralela irregular de posición bifacial y distribución continua.

\section{Tipo (A.01.4) Punta bifacial romboidal de base recta}

Dos artefactos conforman este tipo. El primero de ellos es un fragmento meso basal de punta romboidal bifacial de base recta sobre obsidiana (Lámina I, L-0005), en su tercio superior se observa una fractura por causas tecnológicas. Su longitud es de $37 \mathrm{~mm}$, ancho de $26 \mathrm{~mm}$ y espesor de $6 \mathrm{~mm}$. Su máximo ancho y espesor se localiza en la parte mesial de la pieza. Tiene un peso de 4.34 gr y sus ángulos de borde activo bifacial oscilan entre $40^{\circ}$ y $60^{\circ}$, su silueta es romboidal, de perfil y sección de forma cóncava convexa. La tecnología empleada para los retoques en ambas superficies ha sido la percusión blanda y/o posible presión. En una de sus facetas al cual arbitrariamente le llamamos superficie inferior, se puede notar el negativo originario del soporte o blank, siendo esta una lasca secundaria a percusión dura. Los retoques están sobre un borde de delineación recta convexa, su extensión varía entre corta y larga, inclinación aguda, localizándose en todo el perímetro de la pieza, su morfología es paralela irregular bifacial y distribución continua.

Por otro lado, la pieza L-0007, también del mismo tipo no presenta el ápice. Confeccionada sobre obsidiana de coloración marrón, esta modificada a partir de una lasca secundaria a percusión dura alargada. Su longitud es de $26 \mathrm{~mm}$, ancho de $20 \mathrm{~mm}$ y espesor de $7 \mathrm{~mm}$. Su máximo ancho y espesor se localiza en la parte mesial de la pieza su peso es de 2.93 gr y el ángulo de borde activo fluctúa entre $50^{\circ}$ y $55^{\circ}$. Su silueta es de forma romboidal irregular, su perfil y sección presenta forma biconvexa, la tecnología empleada en la pieza en ambas superficies ha sido la percusión blanda y eventualmente presión, no se ha detectado presencia de córtex. El retoque en esta pieza es recto convexo y de extensión corta irregular, la inclinación es semiabrupta localizándose en todo el perímetro de la pieza, su forma es paralela irregular, de posición bifacial y de distribución continua.

\section{(Tipo A.01.5.) Punta bifacial triangular de base cóncava}

En este tipo se han hallado dos puntas completas, L-0003 y L-0006, ambos sobre obsidiana de colores negro traslucido y pátina brillosa. El soporte para la confección de ambas piezas ha sido posible mediante la obtención de lascas secundarias a percusión dura. El máximo ancho en ambas piezas se localiza en la parte basal de la pieza y sus máximos espesores sobre la parte mesial.

Las medidas de longitud de la primera pieza L-0003, es de $36 \mathrm{~mm}$, ancho de $19 \mathrm{~mm}$ y espesor de $6 \mathrm{~mm}$. Teniendo un peso de 2.24 gr y ángulos de borde bifacial entre $40^{\circ}$ y $45^{\circ}$. Su silueta es triangular, el perfil y sección biconvexa. La tecnología empleada ha sido la presión. La delineación del retoque es ligeramente convexa, extensión corta e inclinación aguda y muy cortante, localizándose en toda la periferia de la pieza. El retoque presenta además una morfología paralela irregular de posición bifacial y distribución corta. La base cóncava de esta punta ha sido reducida por presión teniendo una muesca con una profundidad de $10 \mathrm{~mm}$.

Por otro lado la pieza L-0006, presenta una longitud de $21 \mathrm{~mm}$, ancho de $18 \mathrm{~mm}$ y espesor de $6 \mathrm{~mm}$ siendo su peso de 1.65 gr. El ángulo de borde activo bifacial oscila entre $60^{\circ}$ y $65^{\circ}$. $\mathrm{Su}$ silueta es triangular, perfil paralelo recto y sección biconvexa. La tecnología empleada ha sido la presión. Con respecto al retoque en esta pieza tenemos que mencionar que la delineación es recta, su extensión corta irregular, inclinación abrupta, exponiendo un filo grueso, localizándose sobre la periferia de la pieza, de morfología paralela irregular, posición bifacial y distribución continua. Hemos inferido a partir de la forma, mediciones de la pieza y peso, que esta fue en un inicio de mayor longitud, frac- 
turándose en el proceso de puesta en forma. Luego el borde fracturado fue modificado por precusión blanda. Su pequeño tamaño indica su aprovechamiento máximo y rehuso del débitage.

\section{(Tipo A.01.6.) Punta bifacial lanceolada de base cóncava}

Se trata de una única pieza, (Lámina IV, L-0029), definida como un fragmento meso basal de punta bifacial lanceolada de base cóncava tallada sobre una calcedonia de fractura concoidal. Presenta una longitud de $25 \mathrm{~mm}$, ancho de 35 $\mathrm{mm}$ y espesor de $7 \mathrm{~mm}$, su peso es de $5.22 \mathrm{gr}$. Su máximo ancho y espesor se localizan en la parte mesial de la pieza. La base cóncava presenta una ligera muesca que tiene un ángulo de $40^{\circ}$. El ángulo de borde bifacial oscila entre $40^{\circ}$ y $60^{\circ}$. $\mathrm{Su}$ silueta es trapezoidal, perfil triangular y sección cóncava convexa. La tecnología empleada ha sido la percusión blanda y eventualmente la presión. El retoque se delinea de una forma convexa, su extensión es corta, inclinación semiabrupta localizándose en los bordes izquierdo y derecho de la pieza. Su morfología es paralela irregular, posición bifacial y distribución continua. Presenta una fractura transversal tecnológica en la parte mesial. A juzgar por la forma de su perfil, ancho de $35 \mathrm{~mm}$ y peso de esta pieza hacen suponer que se encuentra aún en el proceso final de elaboración.

\section{A.02. Preformas de bifaz y/o puntas (Tipo A.02.1.) Preforma de bifaz}

Estamos frente a un fragmento meso basal de una preforma de punta bifacial, (Lámina III, L-0039). Tallada sobre una calcedonia de muy buena fractura, el soporte elegido para su confección ha sido una lasca secundaria a percusión dura alargada, su longitud es de $43 \mathrm{~mm}$, ancho de $36 \mathrm{~mm}$ y espesor de $11 \mathrm{~mm}$. Su peso específico es de 16.73 gr. Su máximo ancho se localiza en el tercio inferior de la pieza y su máximo espesor en la parte mesial del artefacto. El ángulo de borde bifacial oscila entre $45^{\circ}$ y $50^{\circ}$. Siendo su silueta de forma rectangular, perfil de forma recto paralelo y sección biconvexa. La tecnología empleada en la superficie superior e infe- rior ha sido la percusión dura y eventualmente percusión blanda, notándose además aristas no muy pronunciadas sobre ambas facetas. No hay presencia de córtex, lo cual hace pensar en su estado avanzado de reducción y de posible fase de regularización. Se ha documentado retoques en esta pieza, teniendo una delineación convexa, extensión que flutúa entre corta a larga; la inclinación oscila entre aguda a semiabrupta, localizándose en toda la periferia de la preforma. Finalmente la morfología es paralela irregular, de posición bifacial y distribución continua. La fractura localizada en la parte media de modo transversal en la pieza ha sido debida a causas tecnológicas.

\section{Tipo (A.02.2.) Preforma de punta foliácea de base recta}

Se trata de una preforma de punta bifacial foliácea de base recta completa, L-0033, la materia prima seleccionada ha sido una obsidiana de muy buena fractura, siendo el soporte una lasca secundaria a percusión dura. Su longitud es de $42 \mathrm{~mm}$, ancho de $25 \mathrm{~mm}$ y espesor de $8 \mathrm{~mm}$. El máximo ancho se localiza en la parte basal de la preforma y su máximo espesor se localiza en la parte mesial. Su peso es de 6.76 gr, el ángulo de borde bifacial oscila entre $40^{\circ}$ y $50^{\circ}$. La pieza presenta una silueta foliácea, perfil cóncavo convexo y sección triangular irregular. La tecnología empleada sobre la superficie superior ha sido la percusión dura y blanda, en su superficie inferior solo blanda. El retoque de la pieza presenta una delineación convexa, su extensión fluctúa entre corta y larga, inclinación semiabrupta, localizándose en todo el perímetro de la pieza, su morfología es paralela irregular, su posición es bifacial y de distribución continua. A juzgar por los datos expuestos estamos frente a una pieza en estado de regularización.

\section{Tipo (A.02.3.) Preforma de punta romboidal de base cóncava}

Se han registrado dos artefactos líticos, siendo uno de ellos un fragmento mesial de preforma de punta bifacial romboidal de posible base cóncava, modificada sobre calcedonia, L-0030 y una preforma completa y sobre obsidiana, L-0031. 
La pieza fracturada, L-0030, de color negro, tiene una longitud de $36 \mathrm{~mm}$, ancho de $23 \mathrm{~mm}$ y espesor de $8 \mathrm{~mm}$. Su peso específico es de 5.36 gr, el máximo ancho y espesor de la pieza se localiza en el tercio inferior, el ángulo de borde bifacial oscila entre $45^{\circ}$ y $65^{\circ}$. Su silueta es romboidal, perfil y sección biconvexo. La tecnología empleada en la pieza es la percusión blanda y presión. El retoque en esta pieza tiene una delineación cóncava convexa, su extensión oscila entre corta y larga, inclinación semiabrupta, localizándose en los bordes derecho e izquierdo de la preforma. La morfología de los retoques es paralela disponiéndose de forma centrípeta, la posición es bifacial y su distribución continua. Las dos fracturas detectadas han sido originadas por causas tecnológicas. Esta preforma aún presenta poca simetría, observándose en una de sus superficies la presencia de una arista longitudinal lo que indica que esta en proceso de reducción.

Por otro lado la pieza completa, L-0031, definida como una preforma de punta romboidal de base cóncava, presenta una longitud de $35 \mathrm{~mm}$, ancho de $18 \mathrm{~mm}$ y espesor de $6 \mathrm{~mm}$. Su peso es de 2.25 gr. el máximo ancho y espesor de este artefacto se localiza en la parte mesial de la misma. Su silueta es romboidal de base cóncava, perfil cóncava convexa y sección triangular. El blank elegido para su confección ha sido una LSPD. La tecnología empleada para su reducción ha sido el percutor blando y no se ha registrado presencia de córtex. Los retoques tienen una delineación recta, su extensión varía entre corta y larga, inclinación aguda, localizándose periféricamente, exhibe una morfología paralela irregular, su posición es bifacial y se distribuye continuamente.

\section{B. Útiles ordinarios}

\section{B.01. Cuchillo}

\section{(Tipo B.01.1.) Cuchillo atípico}

La pieza (Lámina I, L-0012) se trata de un chert modificado de color negro y pátina opaca. El soporte elegido ha sido una posible LSPD alargada, la longitud de este cuchillo es de $57 \mathrm{~mm}$, ancho de $27 \mathrm{~mm}$ y espesor de 8 $\mathrm{mm}$. El máximo ancho se localiza en el tercio inferior y su máximo espesor en la parte mesial de la pieza. Su peso es de 12.04 gr. El ángulo de borde activo del borde derecho e izquierdo oscila entre $45^{\circ}$ a $60^{\circ}$. Su silueta tiene una forma ovalada, lateral recto convexo y sección triangular. Los retoques en esta pieza presentan una delineación convexa, extensión larga, su inclinación oscila entre aguda y semiabrupta, localizándose en toda la periferia de la pieza, su morfología es paralela irregular, posición bifacial y distribución continua. Se observa en una de las facetas de la pieza una arista longitudinal pronunciada.

\section{B.02. Útiles modificados}

\section{(Tipo B.02.1.) UM/LaminillaPB modificada}

Se tiene registrado las piezas L-0020 y L-0024 en este tipo. Ambas talladas sobre obsidiana y de muy buena fractura.

La pieza (Lámina II, L-0020) presenta una longitud de $47 \mathrm{~mm}$, ancho de $21 \mathrm{~mm}$ y espesor de $4 \mathrm{~mm}$. Su máximo ancho se localiza en la parte mesial de la lasca, mientras que su máximo espesor se encuentra muy cerca al talón. Con respecto al talón este tiene un ancho y espesor de $2 \times 2 \mathrm{~mm}$, siendo determinado como puntiforme con ligera preparación en la parte dorsal de la pieza. El peso es de 2.37 gr y el ángulo de expulsión de $80^{\circ}$. El ángulo de borde activo se localiza en los bordes distal y derecho fluctuando entre $10^{\circ}$ y $15^{\circ}$. Su silueta es rectangular irregular, perfil paralelo recto y sección triangular irregular. El bulbo es difuso, presenta en la cara dorsal de la pieza ocho negativos y siete nervaduras de orientación centrípeta. No hay presencia de córtex y su terminación distal es en pluma. Los retoques presentan una delineación cóncava convexa, extensión corta e inclinación aguda, localizándose en el borde distal y borde derecho de la lasca. La morfología es escamosa, de posición directa y distribución discontinua. La tecnología empleada ha sido la presión y el soporte altamente preparado.

Seguidamente, la pieza (Lámina II, L-0024) se trata en realidad de un fragmento meso distal de laminilla a PB modificada. Se ha visto pre- 
visible denominarla en este tipo debido a sus características morfotecnológicas. Sus medidas de longitud, ancho y espesor son de 36x20x3 $\mathrm{mm}$. El máximo ancho y espesor se localiza en la parte mesial de la pieza, su peso es de 2.13 gr, el ángulo de expulsión oscila entre $60^{\circ}$ y $70^{\circ}$. Las modificaciones en la laminilla se localizan sobre el borde distal, derecho e izquierdo al eje de la laminilla y posee un ángulo de expulsión que oscila entre $20^{\circ}$ a $25^{\circ}$. La silueta de esta pieza es rectangular, el perfil recto convexo y sección triangular. El bulbo es difuso y presenta dos negativos longitudinales verticales y una nervadura central típica de las lascas de preparación laminar. La fractura transversal en la pieza presenta una lengüeta motivo por el cual inferimos que se trata de una fractura por causas tecnológicas. El retoque se delinea de forma cóncava convexa, de extensión corta, inclinación aguda, localizándose sobre toda la periferia de la laminilla. Además el retoque presenta una morfología escamosa, siendo su posición cruzada y distribución continua.

\section{(Tipo B.02.2.) UM/LaminillaPD modificada}

Se trata de cinco laminillas modificadas obtenidas a percusión dura. Cuatro están modificadas sobre obsidiana y solo una laminilla modificada en la variedad de jaspe (Lámina III, L-0028). Sus longitudes varían entre 42 $\mathrm{mm}$ y $62 \mathrm{~mm}$, teniendo un promedio de 47,6 $\mathrm{mm}$. El ancho oscila entre $16 \mathrm{~mm}$ y $25 \mathrm{~mm}$ con un promedio de $20,2 \mathrm{~mm}$; el espesor fluctúa entre $5 \mathrm{~mm}$ y $17 \mathrm{~mm}$, teniendo un promedio de $7,8 \mathrm{~mm}$. El peso oscila entre 2.74 gr a 12.64 gr, con un promedio de 5,6 gr. El máximo ancho se localiza en tres de las piezas, L-0025, L-0028 y L-0035, sobre el borde mesial. En la pieza L-0018 en máximo ancho está sobre el borde distal, mientras que la laminilla L-0032 el máximo ancho se encuentra en su lado proximal. Con respecto al máximo espesor se localiza sobre el borde distal en la laminilla L-0018 y en la parte mesial sobre las piezas L-0025, L-0028, L-0032 y L-0035. No se ha detectado córtex. Se han documentado dos talones lisos L-0025 y L-0028, dos talones exfoliados L-0018 y L-0035 y uno fracturado por causas tecnológicas L-0032.
Con respecto a las medidas de ancho y espesor de los talones lisos en las piezas (L-0025 y L-0028), estos tienen medidas de $3 \mathrm{~mm}$ ancho y por $2 \mathrm{~mm}$ de espesor. En las laminillas (L-0025, L-0028) sus medidas son de $5 \mathrm{~mm}$ de ancho por $1 \mathrm{~mm}$ de espesor. El ángulo de expulsión de las cinco piezas oscila entre $55^{\circ}$ a $90^{\circ}$, temiendo un promedio de $70^{\circ}$ a $75^{\circ}$.

La laminilla (Lámina II, L-0018) presenta modificación en el borde distal, derecho e izquierdo; el ángulo de borde activo oscila entre $25^{\circ}$ a $40^{\circ}$, la forma de la silueta es rectangular, vista de perfil es recto paralelo y la sección trapezoidal. El bulbo en esta pieza es difusa, los negativos en la cara dorsal, se presentan en numero de cuatro y tienen una disposición vertical longitudinal. Asimismo las nervaduras en número de tres se delinean de manera longitudinal vertical. La terminación distal de esta pieza esta reflejada dando a notar que no fue exitosa al momento de su obtención. No se ha observado en la cara dorsal los típicos microesquilamientos de preparación previa del soporte para la extracción de laminillas.

Seguidamente, la pieza (Lámina III, L-0025) presenta un ángulo de borde activo que fluctúa entra $40^{\circ}$ y $55^{\circ}$ localizándose las modificaciones sobre los bordes distal, derecho e izquierdo en este útil. La silueta es laminar, perfil paralelo recto y sección triangular. En la ventral el bulbo es prominente y sobre la dorsal se observan dos negativos longitudinales verticales y una nervadura central longitudinal vertical. la terminación distal de la pieza se presenta ligeramente reflejada, finalmente los retoques presentan una delineación cóncava convexa.

La pieza (Lámina III, L-0028) presenta una serie de modificaciones localizados en el borde distal y derecho de la pieza. El ángulo de borde activo fluctúa entre $40^{\circ}$ a $45^{\circ}$. Su silueta es laminar. El perfil y sección cóncavo convexo. Sobre la cara ventral el bulbo es prominente y en la cara dorsal se ha registrado tres negativos verticales longitudinales y dos nervaduras también verticales longitudinales. Se ha registrado pequeños microesquirlamientos típico de la preparación previa a la extracción de la pieza. La terminación distal es buena y cortante, siendo esta una laminilla exitosa. 
La laminilla (Lámina IV, L-0032) presenta modificaciones sobre sus bordes laterales, el ángulo de borde activo oscila entre $45^{\circ}$ a $70^{\circ}$. Su silueta es laminar, perfil triangular inflexa y sección triangular. Sobre la cara ventral el bulbo se presenta difuso y sobre la dorsal se ha observado tres negativos verticales longitudinales y dos nervaduras dispuestas en el mismo sentido. Por último, la terminación distal de la pieza es relativamente gruesa.

El útil L-0035 es una pieza reensamblada y fracturada en la parte mesial por causas tecnológicas, solo se ha presentado modificaciones en su borde derecho. Su ángulo de borde activo varía entre $40^{\circ}$ a $45^{\circ}$. La silueta es laminar, perfil cóncavo convexo y sección triangular. El bulbo no es observable, sobre la dorsal se tiene tres negativos longitudinales verticales y dos nervaduras pronunciadas orientadas en el mismo sentido. La terminación distal es en pluma, obteniéndose una pieza exitosa.

Para concluir con el registro de las laminillas, hemos visto oportuno abordar el retoque de este tipo en conjunto. Los retoques presentan al menos en un 40\% una delineación recta (piezas: L-0018 y L-0035) y en un $60 \%$ una delineación que tiene una tendencia convexa (piezas: L-0025, L-0028 y L-0032). La extensión de los retoques es corta, la inclinación aguda en las piezas L-0018, L-0028 y L-0035 y abrupta en las piezas L-0025 y L-0032. La morfología es un $100 \%$ escamosa. La posición de los retoques ha sido variada, en primer lugar se ha definido las de posición directa L-0018, L-0028 y L-0032; segundo, la cruzada L-0025 y finalmente, la bifacial L-0035. La distribución de los retoques ha tenido una distribución por lo general continua en las piezas L-0018, L-0025, L-0028 y L-0032 y solo una se ha presentado como alternante L-0035.

\section{B.03. Útil a posteriori (UP)}

\section{(Tipo B.03.1.) LSPD modificada a posteriori}

Seis útiles conforman este tipo. Las piezas L-0016, L-0017, L-0022 y L-0027 están modificadas sobre obsidiana y en las otras L-0049 y
L-0054 se encuentran confeccionadas sobre jaspe y silex.

La longitud de estas piezas varía entre 25 $\mathrm{mm}$ a $53 \mathrm{~mm}$, con un promedio de $38.8 \mathrm{~mm}$; el ancho oscila entre $17 \mathrm{~mm}$ a $42 \mathrm{~mm}$, teniendo un promedio de $31.5 \mathrm{~mm}$. El espesor fluctúa entre $3 \mathrm{~mm}$ a $19 \mathrm{~mm}$ con un promedio de $7.5 \mathrm{~mm}$. El peso varía entre $1.13 \mathrm{gr}$ a $47.83 \mathrm{gr}$. Presentando un promedio de 13,3 gr. El ángulo de expulsión de las piezas oscila entre $55^{\circ}$ a $80^{\circ}$ con un promedio de $67.5^{\circ}$.

Con respecto a la pieza (Lámina II, L-0016) presenta una silueta trapezoidal, perfil paralelo recto y sección cóncava convexa. El máximo ancho se localiza en el tercio inferior de la pieza y máximo espesor en su parte mesial. Sobre la cara ventral el bulbo es difuso. Las modificaciones en esta pieza se localizan en los bordes izquierdo, derecho y distal del útil, fluctuando el ángulo de borde activo entre $30^{\circ}$ y $40^{\circ}$. No hay presencia de córtex y sobre la cara dorsal de la pieza se presentan cuatro negativos centrípetos, un negativo central y cuatro nervaduras laterales. El tipo de talón es puntiforme y tiene un ancho de $4 \mathrm{~mm}$ y espesor de $2 \mathrm{~mm}$. Su terminación distal en pluma nos indica que estamos frente a una LSPD modificada exitosa en su extracción.

Por otro lado, la pieza (Lámina II, L-0017) tiene el máximo ancho localizado en la parte mesial de la pieza. El tipo de talón es facetado y presenta un ancho de $5 \mathrm{~mm}$ y espesor de $2 \mathrm{~mm}$. Las modificaciones se localizan en el borde lateral derecho e izquierdo presentando un ángulo de $10^{\circ}$ a $20^{\circ}$. Los retoques tienen una posición cruzada y de distribución continua. La silueta de la pieza presenta forma rectangular. El perfil y sección es de forma cóncava convexa. En la cara ventral el bulbo es difuso y sobre la dorsal solo se observa un gran negativo profundo, sin presencia de córtex.

La lasca (Lámina II, L-0022) presenta un talón facetado cuyas medidas de ancho y espesor son de $9 \mathrm{~mm}$ y $2 \mathrm{~mm}$. El máximo ancho y espesor en esta pieza se localiza en el borde mesial de la pieza. Las modificaciones se localizan en los bordes distal y lateral de la LSPD, presentando un ángulo de borde activo que fluctúa entre $30^{\circ}$ a $50^{\circ}$. La silueta es romboidal y su vista lateral y 
sección es cóncava convexa. El bulbo es difuso y en la dorsal se observa cuatro negativos centrípetos y tres nervaduras. Finalmente presenta una fractura tecnológica reflejada.

El útil L-0027 presenta un talón exfoliado. Sobre el borde distal se localiza el máximo ancho y su máximo espesor sobre la mesial. Las modificaciones se localizan en los bordes lateral izquierdo y derecho contando con un ángulo de borde activo que fluctúa entre $25^{\circ}$ a $40^{\circ}$. La silueta de la pieza es trapezoidal y su vista lateral cóncava convexa y sección triangular. En la dorsal se observan negativos centrípetos y cuatro nervaduras laterales, y sobre la ventral el bulbo es difuso. Una terminación reflejada es registrada sobre el borde distal.

En la pieza (Lámina V, L-0049) se ha observado un talón liso cuyo ancho es de $16 \mathrm{~mm}$ y su espesor $6 \mathrm{~mm}$. El borde distal se encuentra fracturado observándose la típica lengüeta producto de una fractura tecnológica por percusión dura. El ángulo de borde activo de $45^{\circ}$ se localiza sobre los bordes laterales de la lasca. La silueta de esta pieza es rectangular, perfil cóncavo convexo y sección trapezoidal. En la cara ventral el bulbo es prominente y sobre la dorsal presenta tres negativos paralelos verticales y dos nervaduras también longitudinales.

Por ultimo, la lasca modificada (Lámina IV, L-0054) no presenta talón, su máximo ancho y espesor se localiza en la parte mesial del útil. Las modificaciones se localizan en el borde distal y lateral izquierdo de la pieza, teniendo un ángulo de borde activo que fluctúa entre $75^{\circ}$ a $90^{\circ}$. La silueta de la pieza es trapezoidal, perfil paralelo recto y sección trapezoidal. Los negativos en número de nueve se disponen de manera centrípeta, la presencia de córtex es de un $15 \%$.

Con respecto a los retoques de las seis lascas modificadas se ha observado semejanzas en su extensión, siendo de naturaleza corta, inclinación aguda. La posición en la pieza L-0017 es cruzada y en las piezas L-0016, L-0022, L-0027, L-0049 y L-0054 es directa. Asimismo la delineación del retoque en los útiles L-0016, L-0027, L-0049 y L-0054 tienen una tendencia cóncava. Y las piezas L-0017 y L-0022 presentan forma recta. La morfología de los retoques han sido diversos registrando tendencias escamosas en las piezas L-0016 y L-0027, paralelo irregular entre las piezas L-0017, L-0022, L-0049 y L-0054. Finalmente, la distribución de los retoques ha sido discontinua en las piezas L-0016 y L-0054, continua en las lascas L-0017, L-0049 y L-0027 y alternante solo en la pieza L-0022.

\section{B.04. Raederas}

(Tipo B.04.1.) Raedera doble biconvexa sobre LSPD

Las piezas L-0037 y L-0042 conforman este tipo, ambas raederas están modificadas sobre LSPD. La materia prima elegida para su confección ha sido el vidrio volcánico. El blank seleccionado a sido una LSPD. La longitud de las piezas tienen un promedio de $27 \mathrm{~mm}$, ancho de $23 \mathrm{~mm}$ y espesor de $4 \mathrm{~mm}$. El máximo ancho se localiza en la parte mesial de las piezas. El peso tiene un promedio de $3.5 \mathrm{gr}$. Se ha detectado el talón cortical en el útil L-0037, con medidas de $4 \mathrm{~mm}$ de ancho y de $2 \mathrm{~mm}$ de espesor. En la pieza L-0042 el talón se presenta exfoliado. El ángulo de expulsión de las lascas tiene un promedio de $60^{\circ}$ y los bordes retocados de tienen un ángulo que oscila entre $30^{\circ}$ a $45^{\circ}$. La raedera L-0037 tiene una silueta trapezoidal, su vista lateral y sección es de forma cóncavo convexo. Muy diferente a la pieza L-0042 donde la silueta es ovoide, lateral paralelo recto y sección recto convexo. El bulbo en ambas piezas es difuso, en la dorsal no se ha observado presencia de córtex y se trata de lascas exitosas. Sin embargo en la pieza L-0042, el borde distal esta fracturado exponiendo una típica lengüeta. El retoque tiene una delineación convexa, y su extensión corta, de inclinación aguda, posición directa y distribución continua. Con respecto a la localización de los retoques en la pieza L-0037 es periférica y de morfología paralela irregular. Mientras que en la pieza L-0042, el retoque se localiza en los bordes laterales al eje de la lasca definiendo una morfología escamosa. 
(Tipo B.04.2.) Raedera convergente convexa sobre LSPB

Solo el útil L-0048 conforma este tipo. Esta tallada sobre un jaspe rojizo de muy buena fractura, sobre un soporte de LSPB. Su longitud es de $32 \mathrm{~mm}$, ancho de $25 \mathrm{~mm}$ y espesor de $4 \mathrm{~mm}$. El máximo ancho se localiza en la parte mesial de la pieza, el tipo de talón es cortical con un ancho de $8 \mathrm{~mm}$ y espesor de $2 \mathrm{~mm}$. El peso es de 2.78 gr. El ángulo de expulsión fluctúa entre $60^{\circ}$ a $65^{\circ}$. La silueta de la pieza es trapezoidal y su vista de perfil y sección es cóncavo convexo. En la ventral el bulbo es difuso y sobre la dorsal no se distinguen los negativos y nervaduras. Los retoques presentan una delineación convexa, su extensión es muy corta, su inclinación oscila entre aguda a semiabrupta, localizándose en la periferia de la pieza, su morfología es escamosa, posición directa y distribución continua. Esta es la única pieza que ha presentado indicios de manchas negruzcas en su superficie, pudiéndo ser un indicio de exposición al fuego y procedente de un área de actividad domestica.

\section{B.05. Raspadores}

\section{(Tipo B.05.1.) Raspador atípico}

La pieza (Lámina III, L-0044) la hemos denominado raspador atípico debido a su forma inusual y a la modificación abrupta en el borde lateral. Se encuentra modificado sobre un jaspe, siendo el soporte una LSPD, la longitud de la pieza es de $46 \mathrm{~mm}$, ancho de $40 \mathrm{~mm}$ y espesor de $16 \mathrm{~mm}$. El talón es liso con un ancho de $8 \mathrm{~mm}$ y espesor de $10 \mathrm{~mm}$. Su peso es de 28.19 gr. El ángulo de expulsión de la lasca oscila entre $65^{\circ}$ a $70^{\circ}$. La silueta es de forma trapezoidal, lateral paralelo recto y sección triangular. Su máximo ancho se localiza en la parte mesial de la pieza. El borde distal se encuentra fracturado y ligeramente modificado. El ángulo de borde activo se localiza en los bordes laterales de la lasca, oscilando entre $60^{\circ}$ a $75^{\circ}$. En la cara ventral de la pieza el bulbo es prominente, en la dorsal los negativos y nervaduras presentan una disposición centrípeta. El retoque en esta pieza presenta una delineación convexa, de ex- tensión larga, la inclinación oscila entre abrupta a aguda, localizándose estos en los bordes derecho e izquierdo de la pieza, la morfología es paralela irregular, posición directa y distribución continua.

\section{(Tipo B.05.2.) Raspador circular}

Las piezas líticas L-0001 y L-0010, han sido modificadas sobre obsidiana y el soporte de las piezas estan sobre una LSPD.

El raspador circular (Lámina I, L-0001), tiene una longitud, ancho y espesor de 29×29×14 $\mathrm{mm}$ con un peso de $11.53 \mathrm{gr}$; el máximo ancho y espesor se localiza en la parte mesial al eje del útil. El ángulo de borde activo fluctúa entre $50^{\circ}$ a $85^{\circ}$ y el ángulo de expulsión de la lasca varía entre $70^{\circ}$ a $75^{\circ}$. La silueta de esta pieza es de forma circular, perfil plano convexo y sección trapezoidal. Sobre la cara ventral el bulbo es difuso y sobre la dorsal los negativos y nervaduras se muestran en una posición centrípeta. El talón es liso con un ancho de $7 \mathrm{~mm}$ y espesor de $3 \mathrm{~mm}$. El retoque presenta una delineación convexa, extensión corta, inclinación abrupta, localizándose en toda la periferia de la pieza. Asimismo su morfología es escamosa irregular, posición directa y distribución continua.

Por otro lado, la pieza (Lámina I, L-0010), tiene una longitud, ancho y espesor de $22 \times 23 \times 6$ $\mathrm{mm}$, el talón se encuentra exfoliado. El peso de esta pieza es de 2.79 gr. El ángulo de expulsión de la lasca oscila entre $55^{\circ}$ a $60^{\circ}$ y el ángulo de borde activo fluctúa entre $30^{\circ}$ a $60^{\circ}$. Su silueta es circular, su perfil y espesor es cóncavo convexo. Sobre la cara ventral el bulbo es difuso y en la dorsal los negativos y nervaduras se disponen de forma centrípeta. El retoque tiene una delineación convexa, de extensión corta y su inclinación oscila entre aguda a semiabrupta localizándose en la periferia de la pieza.

\section{(Tipo B.05.3.) Raspador sobre lasca}

Hemos documentado un raspador sobre LSPD cuya materia prima es un silex de muy buena calidad para la talla L-0046 y once raspadores sobre LSPD eligiéndose para su confección materias primas como la obsidiana L-0002, L-0004, L-0011, L-0040, L-0041 y L-0043 (Láminas I, 
III y IV), calcedonia L-0045, L-0047, L-0053 (Lámina IV), silex L-0050 (Lámina IV) y jaspe L-0051 (Lámina V) sumando un total de doce raspadores sobre lasca. El soporte para la confección de estos raspadores ha sido efectuado sobre lascas a percusión dura y una a percusión blanda.

El raspador L-0046, confeccionada sobre una LSPB, tiene una longitud, ancho y espesor de 28x25x4 mm. Su peso es de 3,14 gr. El ángulo de expulsión de la lasca oscila entre $60^{\circ}$ a $70^{\circ}$. El ángulo de borde activo se localiza sobre el borde distal y derecho de la pieza presentando una medida que oscila entre $30^{\circ}$ y $55^{\circ}$. La silueta de la pieza es trapezoidal, perfil paralelo recto y sección recto convexo, en la ventral el bulbo es difuso, mientras que en la dorsal los negativos en número de cuatro tienen una disposición centrípeta, sin presencia de córtex. El talón es puntiforme, siendo este un indicio más de su obtención típica por percusión blanda. La obtención de la pieza ha sido exitosa, siendo su borde distal cortante. Los retoques, presentan una delineación convexa, su extensión es muy corta, inclinación semiabrupta, de morfología paralela irregular, posición directa, distribuyéndose continuamente sobre la pieza.

Con respecto a los raspadores obtenidos por percusión dura, que suman un total de once, tienen una longitud de oscila entre $21 \mathrm{~mm}$ a $40 \mathrm{~mm}$, con un promedio de $29,7 \mathrm{~mm}$. El ancho oscila entre $23 \mathrm{~mm}$ a $43 \mathrm{~mm}$ con un promedio de $30,9 \mathrm{~mm}$ y un espesor que fluctúa entre $5 \mathrm{~mm}$ a $13 \mathrm{~mm}$ con un promedio de $8,2 \mathrm{~mm}$. El máximo ancho tiene una tendencia a localizarse en la parte mesial de las piezas. Por otro lado, el peso de las piezas oscila entre 3.19 gr a 19.58 gr, siendo su promedio aproximadamente en 8 gr. Por lo general estos raspadores tienen bordes con tendencia semiabrupta a abrupta. Seguidamente, el ángulo de expulsión de los raspadores cuyos soportes son las lascas oscila entre $45^{\circ}$ a $75^{\circ}$. Con respecto a las siluetas han sido variadas, desde formas circulares, trapezoidales, triangulares y rectangulares. Asimismo el perfil de las mismas, presenta una tendencia a formas cóncavas convexas. En la sección se ha registrado formas trapezoidales, triangulares y cóncava convexa. El bulbo tiene una recurrencia a ser difuso, los negativos por lo general son longitudinales, la- terales y centrípetos. Tres piezas muestran rastros de córtex: un 20\% en la pieza L-0002; en un 95\% en la pieza L-0045 y un 25\% en el útil L-0051. Los tipos de talón recurrentes han sido los tipos liso, diedro, puntiforme, facetado y cortical. Los retoques tienen una delineación convexa, extensión corta, inclinación con una tendencia semiabrupta, localizándose entre el borde derecho, izquierdo y perimétrico. Se ha observado una tendencia paralela irregular en la morfología de las piezas, siendo su posición directa, y distribución continua. Finalmente solo cuatro piezas presentan facturas por tecnología, estas son las piezas L-0041, L-0045, L-0047 y L-0051.

\section{B.06. Unifaz}

\section{(Tipo B.06.1.) Unifaz sobre LSPD}

Se ha registrado la pieza arqueológica L-0009 sobre obsidiana y las piezas L-0013 y L-0038 en jaspe. El soporte de las piezas han sido lascas secundarias a percusión dura.

La pieza L-0009, ha sido determinada como un fragmento de pieza unifacial, tiene medidas de longitud, ancho y espesor de $20 \times 24 \times 5 \mathrm{~mm}$ y peso de 2.42 gr. El ángulo de borde activo fluctúa entre $30^{\circ}$ a $40^{\circ}$, la silueta es rectangular, perfil paralelo recto y sección plano convexo. En la dorsal los negativos son centrípetos, el porcentaje de córtex es de $15 \%$. El retoque presenta una delineación recta, la extensión oscila entre corta y en parte larga. La inclinación es aguda, los retoques se localizan en el borde lateral y distal al eje de la lasca. La morfología es paralela irregular y la posición varía entre directa, inversa y alternante.

Los unifaces L-0013 (Lámina II) y L-0038, presentan medidas de $52 \times 40 \times 11 \mathrm{~mm}$ y $33 \times 17 \times 6$ $\mathrm{mm}$. Los pesos en estas piezas son de $19.46 \mathrm{gr}$ y 2.63 gr. solo en la pieza L-0013 se ha podido reconocer el tipo de talón liso presentando un ancho de $11 \mathrm{~mm}$ y espesor de $8 \mathrm{~mm}$. El ángulo de borde activo en la pieza fluctúa entre $25^{\circ}$ a $50^{\circ}$. Con respecto a la silueta se ha registrado las formas triangular y lanceolada, el perfil es recto convexo y en la sección se tiene formas biconvexa y recta convexa. Las dos piezas presentan negativos centrípetos y no hay presencia de córtex. Ambas piezas presentan una buena 
terminación distal, su borde agudo nos indica que son lascas exitosas. La delineación de los retoques tienen una tendencia convexa, su extensión oscila entre corta y larga y su inclinación es semiabrupta. Tambien, su morfología es paralela irregular y posición directa. La localización de los retoques se ha creido diferenciarlos. En la pieza L-0013 se localiza en el borde izquierdo y derecho, mientras que en la pieza L 0038 se extiende por toda la periferia.

\section{Núcleo}

\section{(Tipo C.01.) Blank de núcleo}

Se trata de la pieza L-0052 (Lámina V) determinada como blank de núcleo ortogonal, se encuentra modificada sobre obsidiana. La longitud es de $50 \mathrm{~mm}$, ancho de $37 \mathrm{~mm}$ y espesor de $26 \mathrm{~mm}$. Las medidas del blank son aproximadamente de $50 \times 40 \times 26 \mathrm{~mm}$. El peso es de 30.70 gr. La silueta es trapezoidal, perfil triangular y sección cuadrangular. El plano de percusión es cortical, solo se ha registrado un negativo siendo el porcentaje de córtex de un 90\%. La tecnología empleada ha sido la percusión dura. El ángulo de la plataforma de expulsión es aproximadamente entre $70^{\circ}$ a $75^{\circ}$, finalmente su distribución es continua.

\section{Desechos de talla}

\section{(Tipo D.01.) LSPB}

Registrado con el código L-0019, se tiene a la lasca secundaria a percusión blanda sobre obsidiana. Su longitud es de $26 \mathrm{~mm}$, ancho de 15 $\mathrm{mm}$ y espesor $2 \mathrm{~mm}$. El Peso es de 0.60 gr. El ángulo de expulsión es de $80^{\circ}$, el borde distal tiene una ángulo agudo que fluctúa entre $5^{\circ}$ a $10^{\circ}$. El tipo de talón es liso de forma rectangular, teniendo un ancho de $5 \mathrm{~mm}$ y espesor de $1 \mathrm{~mm}$. La silueta de la pieza es de forma rectangular, y su vista de perfil y sección tiene forma cóncavo convexo. Sobre la ventral se observa un bulbo prominente y punto de impacto claro. En la dorsal se ha observado tres negativos longitudinales verticales, con dos nervaduras pronunciadas. No hay presencia de córtex y los microesquirlamientos de preparación son claros.

\section{(Tipo D.02.) LSPD}

La lasca L-0034 (Lámina III), esta modificada sobre obsidiana. Su longitud es de $34 \mathrm{~mm}$, ancho de $32 \mathrm{~mm}$ y espesor de $5 \mathrm{~mm}$. Su peso es de 4.70 gr. El ángulo de expulsión oscila entre $50^{\circ}$ a $55^{\circ}$. El borde distal tiene un ángulo de $10^{\circ}$, indicándonos su exitosa obtención. La silueta es rectangular, perfil y sección cóncava convexa. El tipo de talón es facetado, presentando una forma recta convexa y con medidas de 14 x 5 $\mathrm{mm}$. El bulbo es prominente y punto de impacto claro, típica de las lascas a percusión dura. En la dorsal se ha registrado tres negativos centrípetos, es observable los microesquirlamientos de preparación y no hay presencia de córtex.

\section{(Tipo D.03.) LaminillaPD}

La laminilla a percusión dura L-0026 (Lámina III), se encuentra sobre un jaspe de color granate. Su longitud es de $50 \mathrm{~mm}$, ancho de $16 \mathrm{~mm}$ y espesor de $5 \mathrm{~mm}$. El peso es de $4.24 \mathrm{gr}$, el ángulo de expulsión oscila entre $70^{\circ}$ a $75^{\circ}$. La silueta es laminar, lateral cóncava convexa y sección triangular. El tipo de talón es liso presentando una forma rectangular y con un ancho y espesor de $6 \times 1 \mathrm{~mm}$. En la ventral el bulbo es prominente y el punto de impacto es claro. Los negativos en la dorsal están presentes en número de seis y presentan una orientación longitudinal.

\section{(Tipo D.04.) MicroLaminillaPB}

Las piezas L-0014, L-0015, L-0021, L-0023 (Lámina II) conforman este tipo. La pieza L-0015 es un fragmento meso distal de laminilla. Todas se encuentran modificadas por el empleo de percutor blando. Las piezas L-0014, L-0015 y L-0023 están modificadas sobre obsidiana y la pieza L-0021 sobre jaspe. Las longitudes oscilan entre $26 \mathrm{~mm}$ a $40 \mathrm{~mm}$ con un promedio de $33,75 \mathrm{~mm}$; el ancho fluctúa entre $10 \mathrm{~mm}$ a $17 \mathrm{~mm}$ presentando un promedio de $13,5 \mathrm{~mm}$ y finalmente el espesor varía entre $3 \mathrm{~mm}$ a $4 \mathrm{~mm}$ presentando un promedio de $3.25 \mathrm{~mm}$. Por otro lado, el peso oscila entre $0.60 \mathrm{gr}$ a $1.64 \mathrm{gr}$, con un promedio de $1,07 \mathrm{gr}$. Con respecto al ángulo de expulsión este oscila entre $45^{\circ}$ a $70^{\circ}$ teniendo un promedio de $58^{\circ}$. Por lo general, se observa una tendencia a ángulos muy agudos sobre el 
extremo distal, siendo estos de naturaleza exitosa. La silueta varía entre laminar a rectangular alargada, y de perfil y sección cóncavo convexo. Los tipos de talón detectados han sido puntiforme con medidas de ancho y espesor de $4 \mathrm{~mm}$ por $1 \mathrm{~mm}$ (L-0014), exfoliado 8 x $1 \mathrm{~mm}$ (L-0021) y facetado 3 x $1 \mathrm{~mm}$ (L-0023). Sobre la ventral en todas las piezas se ha detectado el bulbo difuso y por lo general el punto de impacto claro. Sobre la dorsal se ha registrado negativos de disposición centrípeta sin presencia de córtex. Los microesquirlamientos de preparación han sido detectados en todas las piezas menos en el lítico L-0015, por ser una pieza fracturada.

\section{Discusión}

La información que hemos recuperado a partir del análisis lítico de la colección Arcata, nos ha hecho ver lo difícil de establecer asociaciones locales y regionales en la sierra Sur peruana, aplicados desde el punto de vista de la morfotecnología lítica. Esto se debe a la inexistencia de análisis similares como la que hemos efectuado sobre esta colección. El registro métrico de las piezas, las observaciones tecnológicas y el análisis geológico, han permitido demostrar toda una gama de útiles modificados.

En primer lugar, hemos ordenado lo mejor posible las piezas arqueológicas líticas por tipos a partir de la morfotecnología. Además, somos conscientes que la tipología propuesta aquí, puede ser superflua sin la debida relación estratigráfica. Sin embargo, esta puede arrojarnos nuevos datos que a futuro puedan ser usadas comparativamente desde el punto de vista morfotecnológico.

Seguidamente, el análisis geológico nos ha permitido observar la predilección a elegir materia prima con alto grado de silicificación. Esto se ve claramente en el cuadro № 2, en donde la predilección ha sido el seleccionar obsidiana en un porcentaje de $63.5 \%$, seguido de jaspe en un $25.4 \%$, luego de calcedonia en un $7.35 \%$, chert en un $1.8 \%$ y la baja predilección de silex en un $1.8 \%$ para la confección de una serie de útiles e.g. raspadores, laminillas modificadas, raederas y piezas bifaciales. Este tipo de conducta por el aprovisionamiento de rocas con alto grado de silicificación para la obten- ción de soportes y confección de útiles ya ha sido observada por el Dr. Elmo León, en otros yacimientos arqueológicos e.g. El Ring, Quebrada Jaguay, etc. (comunicación personal León 2005; León 2007: 153; 155). La presencia de estas rocas queda al descubierto al momento de realizar el estudio geológico del cuadrángulo de Orcopampa (hoja 31-r) y Cayarani (hoja 30-r) donde se ha registrado desde el punto de vista geomorfológico que, el yacimiento de Arcata, se localiza en la zona de volcanes del Barroso, situada al NNE del cuadrángulo de Orcopampa y al extremo sur del cuadrángulo de Cayarani. Aquí las altas cumbres del Grupo Barroso se encuentran en proceso de destrucción, siendo estas modificadas desde la última glaciación del Pleistoceno. Los tipos de roca estudiados son de origen local y pueden ser encontradas a lo largo de la alineación de volcanes en el cerro Antapuna las cuales tienen una dirección $\mathrm{N} 70^{\circ} \mathrm{O}$; como también al sureste de Antapuna y en los cerros Sani y Chuquihua los cuales están conformados por aparatos volcánicos (Caldas 1993: 7-9, 32). Creemos que es importante mencionar que esta alineación volcánica del Grupo Barroso, merece mayores estudios, pues las posibles actividades volcánicas en el pasado pueden haber alterado el $\mathrm{CO}_{2}$ en la atmósfera, jugando así un rol primordial en la alteración de los fechados radiocarbónicos. Refiriéndonos, a la litología del Grupo Barroso, esta conformado por cuarzos, derrames de rocas volcánicas lávicas y piroclásticas de naturaleza andesítica, variando a dacíticas con tonalidades grises claras a oscuras (Caldas 1993: 31-33). Como se ha dicho antes, el análisis petrográfico, nos ha llevado a demostrar la amplia presencia de obsidiana y jaspe en la colección $(88.9 \%)$ y en pequeñas proporciones de calcedonia, chert y silex (11.1\%) los cuales todos son de origen piroclásticos. Estos datos asociados con los estudios geológicos en la zona de Arcata, posiblemente pueden evidenciar una adquisición de materia prima local. Sin embargo, para hacer valedera esta hipótesis, se requiere de estudios de campo y de prospección en la zona de Arcata.

Con respecto a la obsidiana, estudios de análisis de activación de neutrones (NAA) y difracción de rayos X (XRF) sobre esta materia 
prima ha determinado la existencia de canteras de este vidrio natural en los Andes Centrales los cuales han sido empleados por el hombre como fuente de aprovisionamiento desde el Periodo Precerámico hasta el Horizonte Tardío. Al menos durante el Periodo Precerámico se ha empleado la obsidiana debido a su presencia en los sitios arqueológicos de Pikimachay, Uchkumachay, Telarmachay, Paloma, Asana, entre otros (Burger, et al. 1979: 289-320; 1993: 189-251; 2000a: 267; 2000b: 272-288). Posteriormente, trabajos puntuales han puesto al descubierto y analizado las canteras de obsidiana en las zonas de Alca y Cotallaulli (Chivay) ${ }^{2}$ en Arequipa, como también se ha determinado su origen en las zonas de Quispisisa, Jampatilla y Puzolana en Ayacucho (Brooks et al. 1997: 449-450; Brooks 1998: 433-462; Jennings et al. 2002; Burger et al. 1998a; 1998b; 1998c; 2000a; 2002; 2006; Burger 2006; Tripcevich et al. 2009; 2011; Tripcevich 2007; 2009). ${ }^{3}$ Un dato interesante, es el aprovisionamiento de esta materia prima a finales del Pleistoceno e inicios del Holoceno, documentado en Quebrada Jaguay (QJ-280) por Sandweiss y su equi-

2 La fuente de obsidiana de Cotallaulli fué descubierta por Sarah Brooks y Pedro Huaracha, en la cuenca del río Japo, valle del Colca. El volcán Cotallaulli fue reconocido por Sara Brooks el 13 de marzo de 1994 (Brooks et al. 1997: 449-450; 1998: 433-442). Un posterior trabajo realizado por Burger et al. (1998b), determina que la fuente de obsidiana del "tipo cuenca del Titicaca" se localizada muy cerca del $\mathrm{C}^{-}$Ancachita y la denomina como fuente Chivay, sin encontrar la fuente original procedente de la boca del volcán Cotallaulli. Asimismo el autor menciona no haber podido localizar el volcán en mención por no encontrase en los mapas del IGN (1998b: 204). Sin embargo, Brooks claramente en un mapa del IGN (1967, Hoja 16-g, escala 1:200,000), expone la referencia geográfica de Cotallaulli. Finalmente queremos añadir en este punto dos cosas: 1) Hemos encontrado la referencia geográfica "Cotayaulli", localizado en: "Terrs., Prov. De Cailloma, dist. De Chivay", en el Diccionario Geográfico del Perú (Stiglich, 1922: 301) y 2) Nos mostramos de acuerdo con Sarah Brooks en utilizar el nombre geográfico original donde se localiza la fuente de obsidiana principal, en este caso Cotallaulli o Cotayaulli.

3 Antes de abordar los datos de la obsidiana, queremos alertar al lector que hemos observado una serie de incongruencias con respecto al empleo de la cronología y sus distintas propuestas metodológicas. Esta se viene usando de forma indiscriminada y entremezclada sin conocimiento científico. po de investigación (Sandweiss et al. 1998). El autor menciona haber encontrado desechos de talla lítica, artefactos con trabajo bifacial, sin presencia de puntas de proyectil y pequeñas piezas de obsidiana. Sin embargo, treinta lascas de obsidiana fueron analizadas por activación de neutrones, concluyendo que las piezas provienen de la fuente de Alca en Arequipa, localizada a $130 \mathrm{~km}$ de distancia desde la costa. Además, argumenta tentativamente que la posible no presencia de obsidiana procedente de la cantera de Cotallaulli (Chivay), se debe a que ésta estuvo cubierta por un posible reavance glaciar durante el Yunger Dryas (ca. 11.000 a 10.000 BP) (Sandweiss et. al., 1998: 1831; 1832; Jennings et al. 2002: 111; 116). También, podemos sumar en este punto las referencias sobre el estudio de material lítico del periodo Precerámico Tardío procedente de los niveles 21, 23 y 24 del sitio Ch'uxuqullu extremo sur del Lago Titicaca donde se ha determinado que la obsidiana del tipo "Hoya del Titicaca" fue la seleccionada para la confección de artefactos (Stanish 2002 et al.: 448-449). Hoy sabemos que la fuente de aprovisionamiento proviene de Cotallaulli (Chivay) localizado en valle del Colca, departamento de Arequipa (Brooks 1998: 433-442). Esto pone en evidencia que la geografía andina no ha sido obstáculo para el desplazamiento del tallador prehistórico llegando a recorrer en algunos casos desde la cuenca del Lago Titicaca hasta la región Sur central de los Andes circa 275 km (Stanish 2002 Op. cit.: 451). Este tipo de movimiento humano para la explotación de material idóneo para la talla, no debe de causar extrañeza ya que para la transición del Paleolítico Medio y Paleolítico Superior Europeo, exactamente para los yacimientos arqueológicos de la Roc-de-Combe y la Côte, han brindado a partir de los estudios de morfotecnología lítica y petrográfica del Châtelperronien (ca. 33.000-40.300 BP), conocimiento de desplazamientos interregionales humanos para la explotación de fuentes de materia prima que distan entre $5 \mathrm{~km}$ a $100 \mathrm{~km}$ (Pelegrin 1995: $193-201 ; 242-245 ; 266-267)$.

Desde nuestra zona de estudio en Arcata, hemos podido examinar que la cantera de obsidiana más próxima es la denominada Alca, localizándose en línea recta a $52 \mathrm{~km}$ al oeste de 
nuestra zona de estudio, hipotéticamente esta podría ser una fuente local de posible aprovisionamiento para la zona de Arcata. Pero el aprovisionamiento de material lítico y en especial la obsidiana, viene siendo extraída desde grandes distancias al menos desde inicios del Holoceno (e.g. Quebrada Jaguay, Asana). Hipotéticamente creemos que el desplazamiento aproximado de $110 \mathrm{~km}$ en línea recta hasta la fuente de Cotallaulli (Chivay), no es problema alguno para el poblador andino. Seguidamente, otra fuente de obsidiana como la de Quispisisa se localiza a una distancia de $86 \mathrm{~km}$ al noroeste del sitio de Arcata. Recalcamos que el aprovisionamiento de materia prima y desplazamiento humano a grandes distancias durante el Periodo Precerámico son posibles en el área andina, dejando abierta la posibilidad de extracción de obsidiana desde otras posibles fuentes. Un ejemplo claro de movimiento a larga distancia durante el Horizonte Temprano, puede argüirse del estudio por NAA y XRF sobre los artefactos de obsidiana de Chavín de Huantar proveniente de los contextos Janabarriu, Urabarriu y Chakinani los cuales han confirmado que la materia prima de los artefactos modificados de Chavín han sido extraídas principalmente de la cantera de Quispisisa en Ayacucho y en menor proporción de la fuente de obsidiana de Alca en Arequipa, las cuales distan aproximadamente entre 470 a $770 \mathrm{~km} \mathrm{al}$ sur de Chavin (Burger et al. 1998c: 246).

Con respecto al análisis morfotecnológico lítico de las piezas arqueológicas de Arcata merece una mención a parte. Las puntas bifaciales suman un total de ocho piezas (Cuadro 1), siendo el $14.5 \%$ del material lítico. Se trata de piezas bifaciales terminadas a percusión blanda y/o presión. El blank seleccionado para la talla de estas piezas han sido al parecer lascas alargadas. Las formas trapezoidal, romboidal y triangular son las recurrentes. Tres de las puntas bifaciales estan fracturadas por tecnología observándose la típica lengüeta las cuales hipotéticamente pudieron haber sido originadas durante la talla. Se trata de piezas bien configuradas en su simetría y sin aristas agudas sobre su superficie.
En el caso de las preformas de bifaz y/o puntas conformados por un total de 4 piezas (7.25\%), se ha observado el empleo de percusión dura, blanda y eventualmente presión y no hay presencia de córtex, presentando aristas pronunciadas en su superficie superior e inferior, que desvirtúan su simetría. Nuevamente, el blank elegido ha sido la predilección de lascas a percusión dura alargadas.

Un único cuchillo, conformado por el 1.81\% de la colección, ha sido confeccionado a partir de una lasca a percusión dura alargada, a juzgar por sus medidas $(57 \times 27 \times 8 \mathrm{~mm})$, podría tratarse de una lasca con tendencia laminar, el ángulo de borde activo es entre aguda y semiabrupta, típica en los cuchillos y posiblemente una de sus funciones pudo haber sido el cortar material blando.

Los útiles modificados nos han parecido sumamente interesantes, si bien es una muestra pequeña, estas han sido determinadas como laminillas obtenidas por percusión blanda y dura, sumando un total de siete piezas (12.72\%).

Las dos laminillas modificadas a percusión blanda, presentan retoques en los bordes dístales y laterales, de filos agudos. Sus medidas básicas de longitud y ancho las delatan como laminillas. En la pieza (Lámina II, L-0020), los negativos y nervaduras tienen una orientación centrípeta y talón liso con microesquirlamiento de preparación en la dorsal; mientras que en la pieza (Lámina II, L-0024) se encuentra fragmentada, pero sus medidas la delatan como laminilla, además se ha podido apreciar dos negativos longitudinales verticales y una cresta longitudinal central, esta disposición de negativos longitudinales paralelos y una arista también en su misma disposición hacen posible relacionarla con la preparación de núcleos para la extracción de láminas.

Si bien es solo una pieza detectada a percusión blanda, a esto se suman cinco laminillas modificadas, obtenidas a percusión dura lo cual hace pensar en la preparación de núcleos para la obtención de estas piezas. Las hemos diferenciado de las piezas a percusión blanda por su espesor, la profundidad de los negativos en la cara 
dorsal y su peso relativo entre $2.74 \mathrm{gr}$ a $12.64 \mathrm{gr}$, presentando un promedio de 3.88 gr. A esto se suma el tipo de talón liso al menos en dos piezas enteras que tienen una medida promedio de $4 \mathrm{~mm}$ de ancho y espesor de $2 \mathrm{~mm}$, con puntos de impactos claros y bulbos entre prominente a difuso (L-0025 y L-0028). Al menos en la pieza (L-0025) se ha observado la típica preparación dorsal definida como microesquirlamientos localizada en la parte proximal de la cara dorsal de la pieza. En estas cinco laminillas a percusión dura, se destacan por presentar entre 2 a 4 negativos longitudinales verticales y paralelos al eje de la lasca y con nervaduras o crestas longitudinales. Todas las piezas tienen una buena terminación distal. Solo la pieza (Lámina II, L-0018) presenta hinge o reflejo que ha sido posteriormente modificado.

Este tipo de tecnología para la extracción de laminillas requiere mayores atenciones, por su alto grado de preparación y destreza en su obtención. No hemos encontrado en la colección, los núcleos de donde se obtienen estas piezas, pero estas laminillas delatan su asociación con núcleos de obsidiana altamente preparados para la obtención de lascas laminares o en este caso laminillas. Hemos tratado hasta donde nos ha sido posible hacer relaciones regionales pero las mismas han sido casi infructuosas. Sin embargo, posibles evidencias de tecnología laminar se han registrado en el abrigo de Toquepala (TaL-2). Ravines, en su análisis tipológico clasifica "láminas y astillas" provenientes de los cinco estratos arqueológicos del abrigo (Ravines 1971: 118). Seguidamente, más adelante define a los núcleo en tres tipos, siendo los del "tipo A": "Núcleos poliórficos de bloques" (sic!) (Debería decir polimórficos); definiéndolas de la siguiente manera:"...estas piezas tienen cierta preparación, pero en su mayoria se reducen a planos de lascado negativos y facetas orientadas en diversos sentidos. En algunos ejemplares estas cicatrices corresponden a negativos de astillas laminares de lados más o menos paralelos, $o$ astillas pequeñas de lados paralelos y fracturas en bisagra que han dejado un bulbo de percusión negativo bien visible" (Ravines 1971: 119). Luego, en su misma tipología define: "Núcleos piramidales" denominando a los del "tipo B" como sigue: "puede definirse como un núcleo de forma discoidal, con preparación final simple, o sin ella. La forma circular de su contorno; visto desde arriba, se debe fundamentalmente, al astillado regular hecho desde un solo lado, para obtener pseudo-láminas o astillas de lados más o menos paralelos". Y finalmente, los núcleos piramidales del "tipo C" los define como: "...estos núcleos se caracterizan por presentar planos negativos de lascado, obtenidos desde puntos opuestos o alternos. A diferencia del tipo B, estos núcleos, se caracterizan mayormente por haber producido laminares y/o lascas largas de lados casi paralelos." (Ravines 1971: 120, 121). Estas descripciones nos brinda la idea de haber sido registrado posibles núcleos preparados para la extracción de láminas y/o laminillas, al parecer la materia prima empleada en este abrigo han sido la andesita, riolita, un tipo denominado vitrófiro riolítico y roca máfica, pero el registro sobre los mismo es deficiente y su asociación estratigráfica no es clara. Además a esto se suma los contradictorios datos obtenidos de los fechados radiocarbónicos e.g. del estrato 3 (cal. 4,895-4,595 a.C) y estrato 5 (cal. 4,487-4,274 a.C) (cf. León 2007: 230).

Otro yacimiento que merece ser citado, es la cueva del Guitarrero (Pan 14-102), Thomas Lynch (1980), tiene registrado un conjunto de piezas laminares las cuales han sido clasificadas por su morfotecnología en cuatro tipos definiendolas como: "Quishqui Puncu type 53a; Quishqui Puncu type 53b; Quishqui Puncu type 54a; Quishqui Puncu type 54b y Quishqui Puncu type 55". Desde nuestro punto de vista y siempre tomando el aspecto morfotecnológico de estas piezas, hemos notado que las mimas pueden encajar perfectamente como lascas laminares, microlaminillas y laminillas tal como lo ha definido el mismo Lynch. Llama la atención la obtención de estas piezas sobre cuarcitas, rocas afaníticas y sílice criptocristalina de grano fino, siendo estas de alto grado de silicificación, las cuales tienden a la vitrificación como en el caso de las rocas criptocristalinas. Esto no hace más que confirmar la selección de materia prima con un alto grado de contenido de sílice. El registro de estas láminas, laminillas y microlaminillas en la cueva del Guitarrero ha sido de mejor entendimiento, se sabe que estas piezas presentan los microesquirlamiento de preparación para su 
obtención, además han sido al menos dibujados y se puede inferir de las figuras (vide, Lynch 1980: 216, figure 9.17: blades: b, c, d, e, f, g, l, m, s, t, u, v, w, x, y, z, aa, gg, ii, jj, kk, mm, nn, oo, pp y ss) que en sus facetas dorsales existe la presencia de largas crestas longitudinales acompañadas de dos negativos también longitudinales y paralelos unidireccionales como también se observa lascas con negativos orientados bidireccionalmente, lo cual induce a pensar en núcleos preparados para la extracción láminar de reducción no solo unidireccional sino también bidireccional. Lynch ha registrado una serie de núcleos desbastados sobre guijarros, pero ninguno de estos tiene negativos paralelos y la preparación exclusiva que evidencie la obtención de lascas laminares (vide Lynch 1980: 218, figure 9.18). La presencia de esta técnica ha sido registrada en todos los estratos de la cueva de Guitarrero, pero su alta recurrencia recae en el Complejo estratigráfico IV, con un total de 132 piezas (cf. Lynch 1980: 212). Hay que tener en cuenta que este yacimiento no se salva de los problemas de estratigrafía y/o tafonómicos. Un total de diecisiete fechados radiocarbónicos se han tomado en este sitio. Si bien no es el tema principal abordar la revisión de los fechados radiocarbónicos, al momento de la calibración con la curva del hemisferio sur (Oxcal v3.10) se ha observado que algunas de las muestras más tempranas pueden presentar alteraciones y/o problemas con el rango de extensión de las muestras. Si tomamos como valederas los fechados radiocarbónicos que no evidencian problemas al momento de la calibración tenemos que en la cueva de Guitarrero se ha tenido una ocupación en asociación a tecnología laminar que va desde cal. 9,251 a 5,981 a.C.

Por otro lado, en el estrato superior, denominado Complejo IV de la cueva Guitarrero, se han tomado dos fechados radiocarbónicos, el contexto de procedencia de las muestras presenta problemas de disturbios pero, han sido aclarados por el autor de la excavación (Lynch 1980: 42). Se ha observado que, la mayor gama de microlaminillas, laminillas y láminas provienen de este estrato y nos hemos atrevido a calibrar el fechado que correspondería a una edad Precerámica (SI-1503; 8225 990 BP) este nos ha arrojado cal. 7,325-6843 a.C. siendo aún más temprano que lo obtenido para el yacimiento de Toquepala. Empero, esta muestra radiocarbónica del complejo IV de la cueva de Guitarrero también debe tomarse con mucho cuidado debido a su procedencia de contexto alterado.

Finalmente, otras referencias sobre tecnología láminar, es la propuesta por Michel Collins para la cultura Clovis (Collins 2002). Collins define los atributos de las láminas, tomando para ello las definiciones de la metodología francesa y adaptándola a la tecnología láminar Clovis para discernir la obtención de láminas intencionales de las no intencionales (Collins 2002: 9). Tales definiciones básicas para distinguir entre láminas culturales y naturales, son distinguidas por cuatro variables: en primer lugar la medida, la forma, cantidad, litología y la disposición de la materia prima; seguidamente como segundo punto las medidas intencionales y las formas de la producción de las láminas. Luego, la estrategia de la reducción, la técnica empleada y finalmente, los artefactos usados o lascas usadas (Collins 2002: 11). No queremos entrar en mayores detalles con la tecnología láminar Clovis, pero dejamos en claro que en este periodo (11,000-12,000 BP) hay indicios de extracción láminar, laminillas, microlaminillas como también, se ha hecho registro de núcleos con preparación para la extracción de este tipo de tecnología. Un ejemplo de lo dicho, se puede inferir de los materiales líticos sobre cuarcita del taller 5GN149, del condado de Gunnison, Colorado (Cooper 2006:85-88) y otras comparaciones pueden ser efectuadas en los yacimientos preClovis e.g. Meadowcroft Rockshelter (36WH297) en Pennsylvania; Cactus Hill, Virginia y Topper Site, South Carolina (Goodyear 2003: 103-111). En estos sitios láminas prismáticas en algunos casos retocados, sobre un exótico chert, pueden ser definidos bajo la metodología francesa como laminillas con medidas entre $30 \mathrm{~mm}$ y $60 \mathrm{~mm}$ datando aproximadamente entre 12,800-15,000 BP.

Hipotéticamente, podemos sugerir, a partir de los datos analizados que esta técnica usada para la extracción de láminas y/o laminillas así como la preparación exclusiva de núcleos, posi- 
blemente se ha mantenido lo largo del tiempo, siendo este un indicio de tradición técnica que se ha mantenido durante casi todo el Precerámico y que ha pasado desapercibido debido a los registros superficiales efectuados sobre el material lítico.

Volviendo a nuestra investigación y con respecto a las seis lascas a percusión dura modificadas a posteriori las cuales suman un $10.90 \%$ de la colección, estas presentan una recurrencia de ángulos de borde activos agudos, de excelentes filos lo cual los hacen propicios para el descarnado o tratamientos de pieles. Al menos una pieza (Lámina V, L-0049) presenta en la dorsal tres negativos longitudinales verticales paralelos, a juzgar por la disposición de los negativos y dos de sus nervaduras en la misma orientación podría asociarsele con la extracción de posibles lascas con tendencia pseudo laminar.

Las raederas y raspadores conforman un total de 18 piezas (32.69\%), estas han mostrado las formas típicas ya registradas morfotecnológicamente en la sierra peruana, al menos para los estratos IV; V inf.; V sup., VI y VII del sitio arqueológico Telarmachay talladas sobre silex fino, cuarcitas y en general volcánicas silicificadas (cf. Lavallée et al. 1995: 75-76; 99-110). Estas son registradas durante todo el precerámico, alcanzando una temporalidad entre cal. 7,5962,131 a.C. Finalmente, tal como se atestigua en Telarmachay estos artefactos pudieron tentativamente haber sido utilizados para el despellejamiento y/o trabajos en pieles (Lavallée et al. 1995: 296)

En los unifaces (5.45\%), elaborados a partir de lascas a percusión dura, no se ha podido notar mayores detalles y/o algún tipo de modificación o brillo sobre sus bordes, es muy probable que a juzgar por sus bordes agudos a semiabruptos pudieran haber formado parte de la gama de instrumentos para el tratamiento de pieles.

Seguidamente un blank de núcleo de forma ortogonal sobre obsidiana conformado por el $1.81 \%$ de la colección, presenta un 90\% de córtex. Este blank nos muestra indicios de la forma natural de la obsidiana elegida, siendo en este caso de origen angulosa.
Finalmente, dos lascas una obtenida a percusión dura y otra a percusión blanda han sido determinadas sobre obsidiana conformando tan solo el 3.62\% del material en estudio. En realidad se trata de dos lascas exitosas en su obtención debido a su terminación en pluma y proceden de reducción bifacial. Las laminillas juegan un rol fundamental y en este caso una de ellas (Lámina III, L-0026) y cuatro microlaminillas (L-0014, L-0015, L-0021 lámina II y L-0023) (9.08\%) conforman este rubro. Estas piezas presentan el típico microesquirlamiento de preparación en la cara dorsal de las piezas. Además talones lisos, facetados y exfoliados han sido registrados. Al igual que las lascas estas son exitosas por su típica terminación en pluma. No presentan los típicos negativos longitudinales paralelos si no más bien los negativos y nervaduras en este caso son centrípetos. Una posible asociación de estas piezas se puede realizar tentativamente con el abrigo Caru (PTa2-5), localizado en el distrito de Tarata, provincia del mismo nombre, departamento de Tacna. Ravines, ha registrado "astillas" definiéndolas como: "... desechos de talla. Su característica principal es ser bastante planas, estrechas, y de muy poco espesor. No se observa ninguna con talón preparado". Estas diez "astillas" sobre cuarzo criptocristalino, han sido medidas en milímetros por Ravines, notándose al menos en dos piezas que su largo es el doble de su ancho $(10 \times 5 \times 3 \mathrm{~mm}$ y $8 \times 4 \times 4 \mathrm{~mm})$ y al menos en cinco piezas la longitud es tres veces la proporción de su ancho $(48 \times 11 \times 8 \mathrm{~mm} ; 18 \times 5 \times 35$ $\mathrm{mm} ; 50 \times 13 \times 13 \mathrm{~mm} ; 31 \times 9 \times 6 \mathrm{~mm}$ y $28 \times 9 \times 5 \mathrm{~mm}$ ) (Ravines 1967: 45). Estas medidas de las astillas (¿lascas?), procedentes del pozo A del abrigo Caru, elucubrativamente hacen pensar en posibles evidencias de asociación con microlaminillas en este yacimiento arqueológico, pero las descripciones y registro morfotecnológico son insuficientes. Se menciona el registro de 10 láminas y 70 lascas en el Pozo B, Estrato 2, asociado a un taller con fogones. Sin embargo, se carece de registros métricos y descriptivos de las piezas. El yacimiento Caru tiene un único fechado (Hv-1083, cueva de Caru 8190土130) que calibrado con la curva del hemisferio sur (Oxcal v.3.10) ha arrojado cal. 7,348-6,836 a.C.; siendo el contexto de donde proviene la muestra no confiable (cf. León 2007: 235; Ravines 1967: 40-43). 
Finalmente, refiriéndonos a la asociación temporal de las piezas líticas de Arcata, estas han sido comparadas desde el punto de vista tipológico, con el Ayanpitinense II, procedente de la provincia de Córdoba en Argentina, aproximadamente entre 6,000 y 4000aC (Schroeder 1957: 291), además, se les ha relacionado con los artefactos del yacimiento de Ichuña, Toquepala y finalmente con algunos útiles procedentes del abrigo Caru (Álvarez 1970: 46; Ravines 1967: 51). Como el lector notará, nosotros hemos tratado de relacionar los registros mas aproximados de estos yacimientos y asociarlos con los materiales de Arcata. A partir de los datos obtenidos de la morfotecnología lítica hemos preferido abordar el tema de la obtención de laminillas, microlaminillas y láminas para proponer de manera amplia la posible asociación temporal de las piezas líticas de Arcata. Si se tomara como valedero el fechado radiocarbónico procedente del pozo B, estrato 2 del sitio arqueológico Caru (cal. 7,348-6,836 a.C.), como también el fechado obtenido para el complejo IV de la cueva de Guitarrero en donde la recurrencia de este tipo de piezas llega al 48\% (cal. 7,325-6843 a.C.), tendríamos una aproximación temporal tentativa para la presencia de esta técnica en la sierra peruana entre los cal. 7,300-6800 a.C. Con respecto a los yacimientos de Toquepala la posible presencia de láminas, según Ravines, esta presente en sus cinco estratos (Ravines 1971: 118) y se tiene dos fechados, el primero en el estrato 3 (cal. 4,895-4,595 a.C) y el segundo en el estrato 5 (cal. 4,487-4,274 a.C). Sin embargo, estratigráficamente los datos son contradictorios, empero estas fechas en alusión a la presencia de tecnología láminar abarca sospechosamente el margen temporal tentativo obtenido de los yacimientos Caru y Guitarrero.

Queremos finalizar, llamando la atención que en la cueva de Guitarrero la presencia de estas piezas está registrada a lo largo de todos sus estratos, si bien hemos tomado presumiblemente al complejo IV como valedero debido a la alta recurrencia de estas piezas laminares (48\%), creemos que podemos extender la presencia de esta tecnología calibrando los fechados de este yacimiento y brindar una extensión temporal amplia, obtenido así un rango de tiempo entre cal. 9,251 a 5,981 a.C. Nosotros, volvemos a repetir, somos concientes de los problemas de estratigrafía en los yacimientos antes expuestos, pero tomamos en este caso como valedero los fechados radiocarbónicos provenientes de la cueva Guitarrero, mediante el cual sugerimos que esta técnica láminar está siendo registrada durante el Periodo Precerámico Temprano con una alta recurrencia y su poca tendiente a su desaparición durante el Precerámico Tardío. En conclusión, las piezas líticas de Arcata, relacionados a la obtención de laminillas, microlaminillas y láminas, pueden asociarse tempralmente entre ca1. 9251-5981 a.C.

\section{Agradecimientos}

Un profundo agradecimiento a los maestros Dr. Duccio Bonavia y Dr. Elmo León Canales. Nuestro aprecio también va dirigido a la Dra. Sarah Brooks por la ayuda brindada. De igual modo, nuestra gratitud al Museo de la Universidad San Agustín de Arequipa (Museo UNSA) y en especial a su director Pablo de la Vera Cruz. También hacemos extenso el agradecimiento a Carlos Del Águila Chávez por la ayuda brindada durante la investigación. 


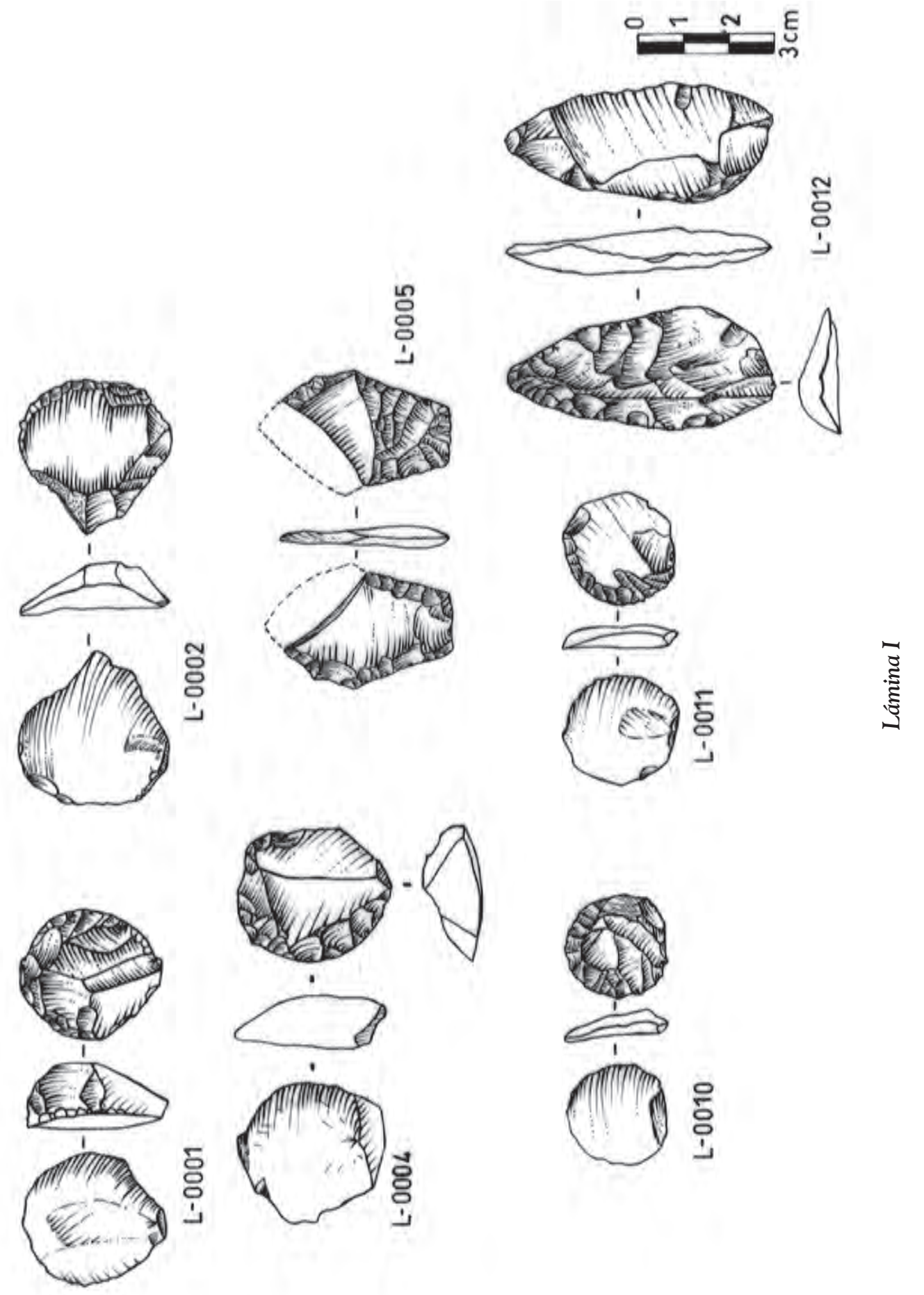



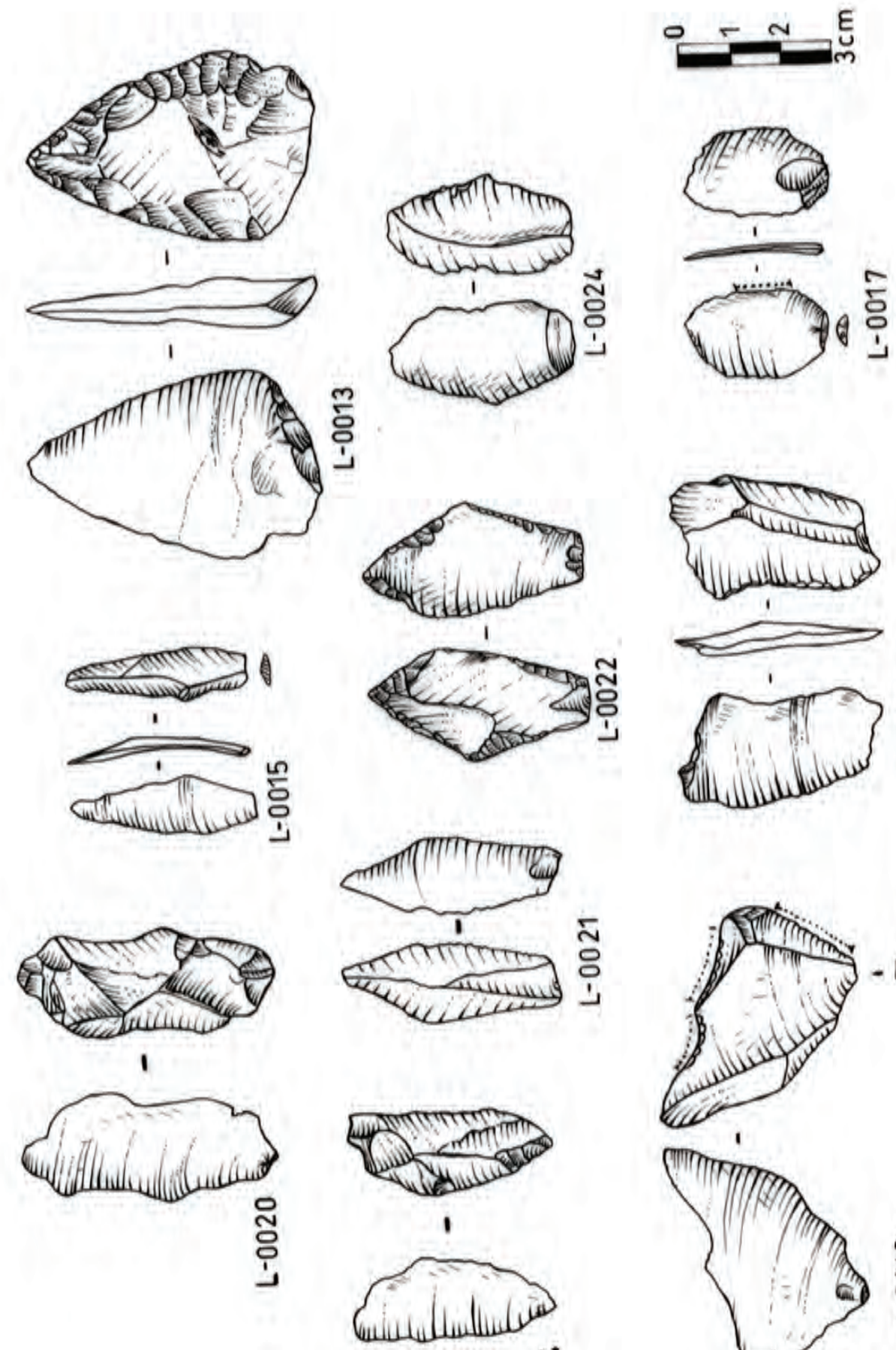

్ㅗㅁ

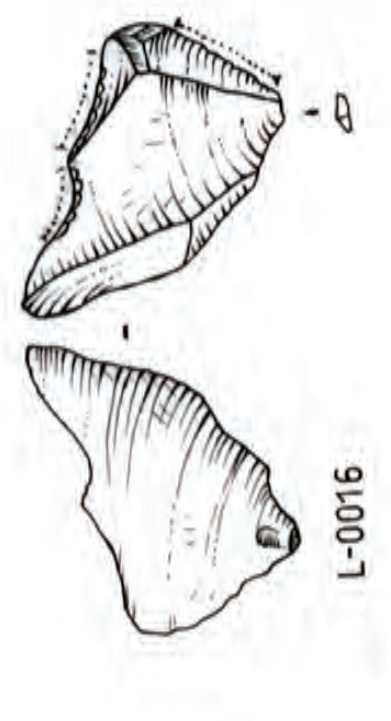




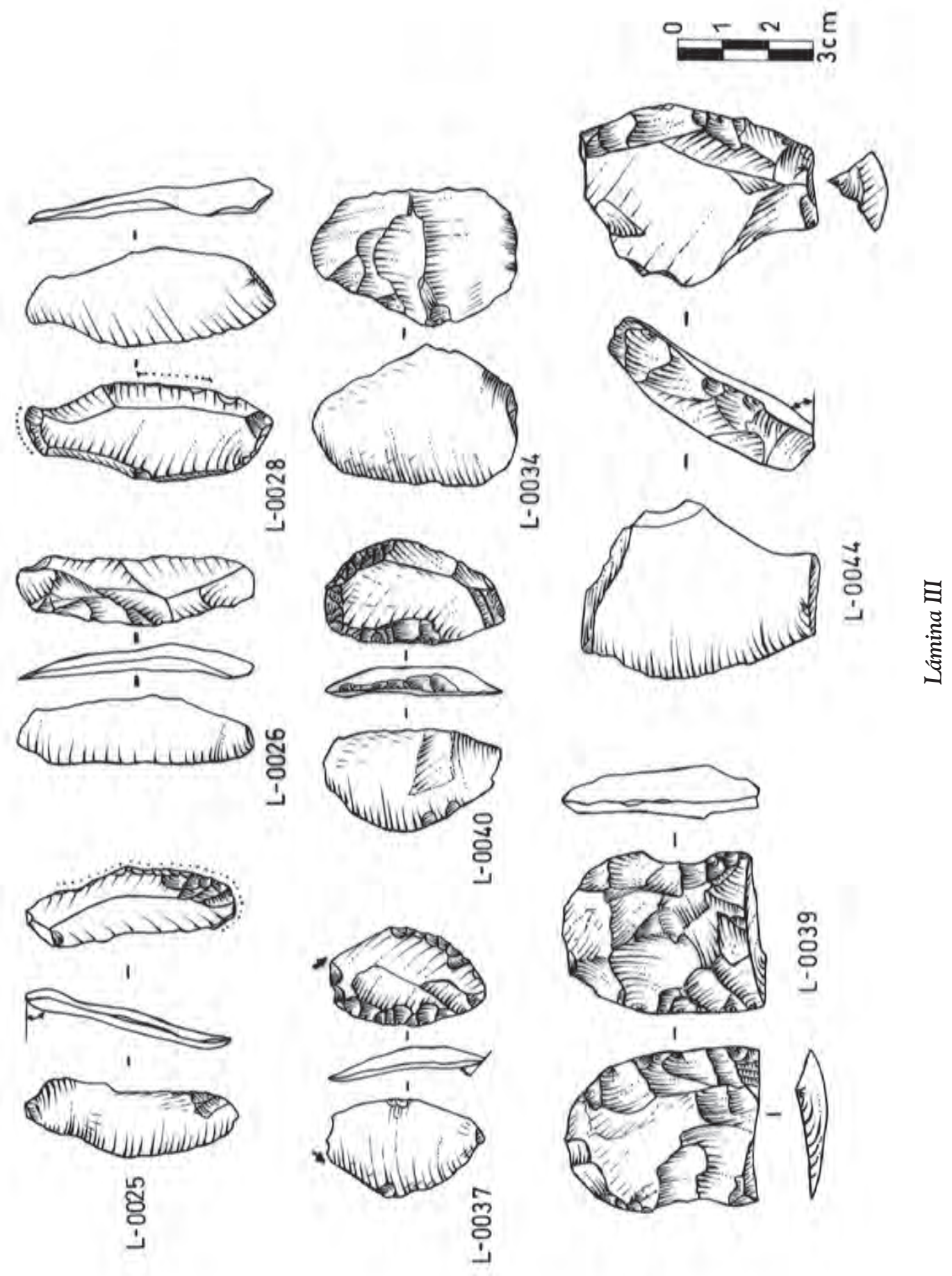




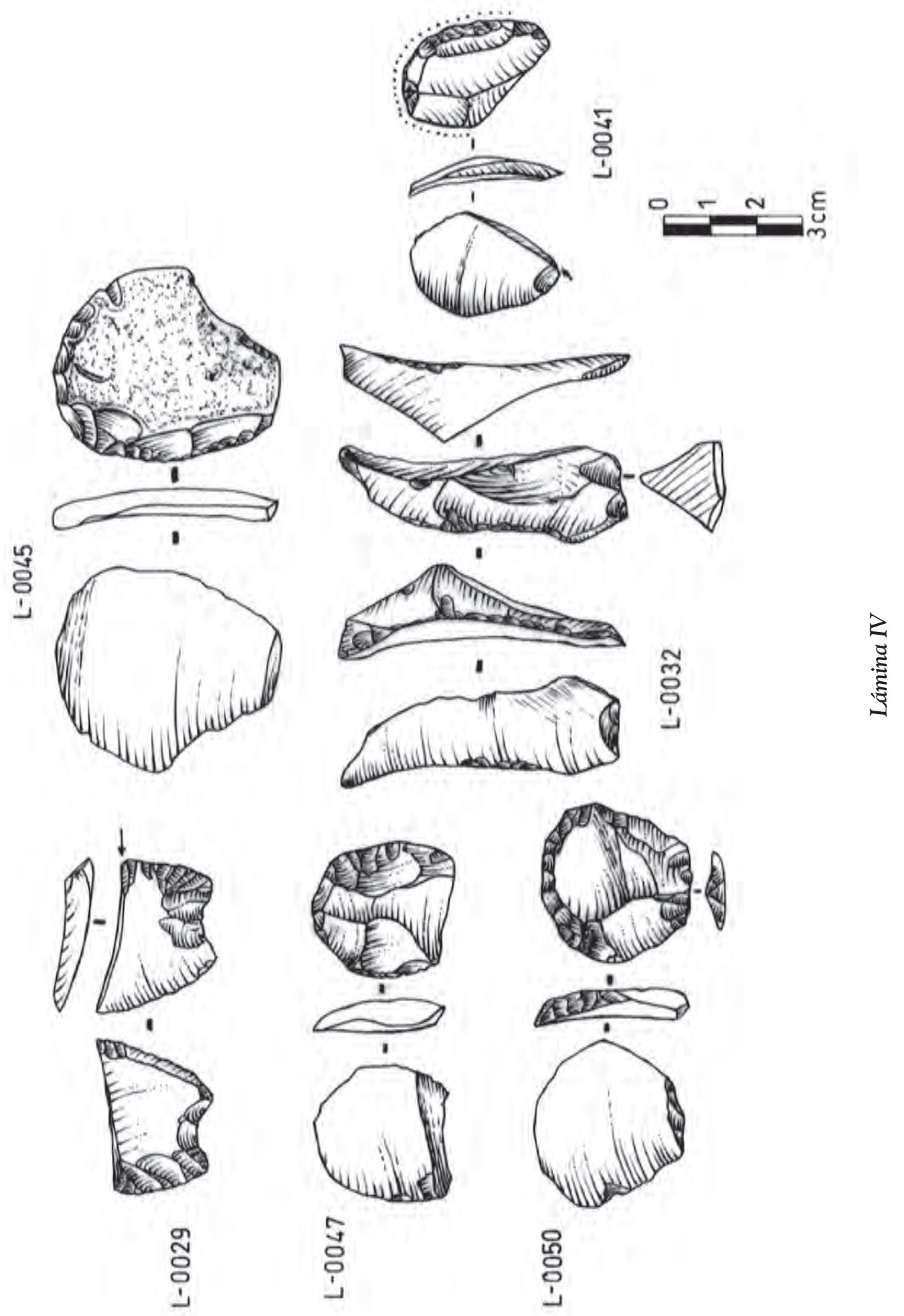




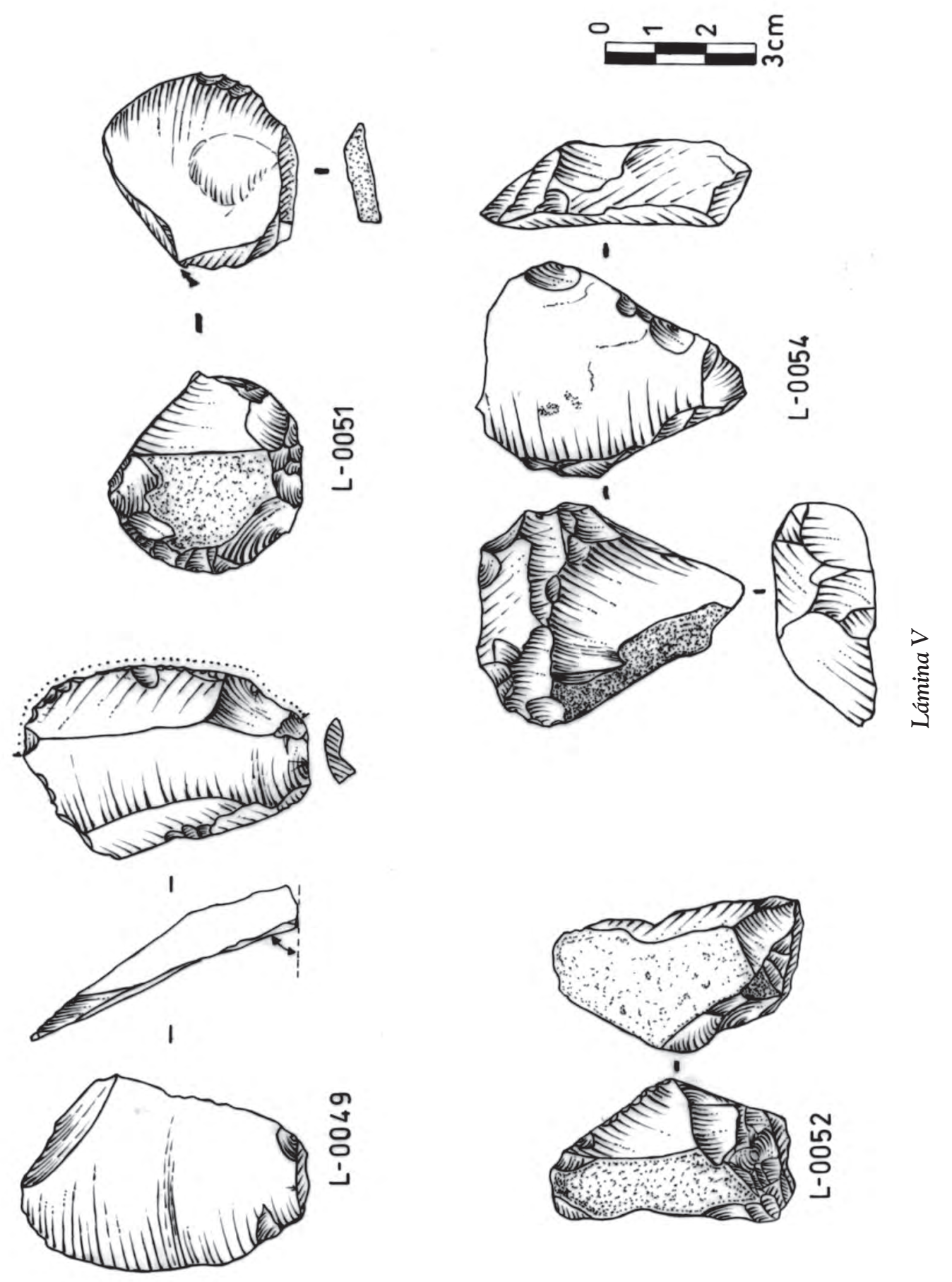




\section{Bibliografía}

Alvarez, Félix

1970 "Informe sobre los materiales de Arcata existentes en el museo donados por el Dr. G. Schroeder". Arqueología y Sociedad, 2. Lima: Museo de Etnología y Arqueología de la Universidad Nacional Mayor de San Marcos, pp. 46-52.

Bonavia, Duccio

1966 "Sitios arqueológicos del Perú (Primera Parte)”. Arqueológicas 9. Lima: Publicaciones del Instituto de Investigaciones Antropológicas. Museo Nacional de Antropología y Arqueología, Pueblo Libre.

1982 Precerámico peruano. Los Gavilanes. Mar, desierto y oasis en la historia del hombre. Lima: Corporación Financiera de Desarrollo S.A. COFIDE-Instituto Arqueológico Alemán.

1992 "Tipología lítica tentativa para el Precerámico final de la Costa Central y Septentrional del Perú". Estudios de Arqueología Peruana. Asociación Peruana para el Fomento de las Ciencias Sociales. FOMCIENCIAS, pp. 83-97.

Bordes, François

1981 Typologie du paleolithique ancien et Moyen. Cahiers du Quaternaire 1. Centre National de la Recherche Scientifique. Centre Regional de publication de Bordeaux.

Brooks, Sarah; Michael Glascock; Martin Giesso

1997 "Source of volcanic glass for ancient Andean tools". Nature. Vol. 386, pp. 449-450. 3 April 1997.

Brooks, Sarah

1998 "Prehistoric agricultural terraces in the Rio Japo basin, Colca Valley, Perú". A dissertation submitted in partial fulfillment of the requirements for the degree of Doctor of Philosophy. (Geography). University of Wisconsin-Madison.

Burger, Richard

2006 "Interacción interregional entre los Andes centrales y los Andes centro sur: el caso de la circulación de obsidiana". Esferas de interacción prehistóricas y fronteras nacionales modernas: Los Andes sur centrales. Instituto de Estudios Peruanos 2006. Historia Andina 32.
Burger, Richard; Frank Asaro

1979 "Análisis de rasgos significativos en la obsidiana de los Andes centrales". Revista del Museo Nacional. Tomo XLIII, pp. 281-325. Lima.

1993 "La distribución y procedencia de artefactos de obsidiana durante el periodo Inicial y Horizonte Temprano". Emergencia de la civilización en los Andes: ensayos de interpretación. Universidad Nacional Mayor de San Marcos. Lima-Perú 1993.

Burger, Richard; Frank Asaro; Paul Trawick; Fred Stross

1998a "The Alca obsidian source: the origin of raw material for Cuzco type obsidian artifacts". Andean Past 5. 1998: 185-202.

Burger, Richard; Frank Asaro; Guido Salas; Fred Stross

1998b "The Chivay obsidian source and the geological origin of Titicaca basin type obsidian artifacts". Andean Past 5. 1998:203-223.

Burger, Richard; Frank Asaro; Helen Michel

1998c "Los artefactos de obsidiana en Chavín de Huantar y sus fuentes geológicas". En Excavaciones en Chavín de Huantar. PUCP, 1998: 244-251.

Burger, Richard; Michael Glascock

2000a "Locating the Quispisisa obsidian source in the department of Ayacucho, Perú". En Latin American Antiquity, 11 (3), 2000, pp, 258-268.

2002 "Tracking the source of Quispisisa type obsidian from Huancavelica to Ayacucho". En Andean Archaeology I: variations in sociopolitical organization. New York: Kluwer academic - Plenum publishers, 2002.

Burger, Richard; Karen Mohr; Sergio Chávez

2000 b "Through the glass darkly: prehispanic obsidian procurement and exchange in southern Peru and northern Bolivia". En Journal of World Prehistory, Vol. 14, № 3, 2000.

Burger, Richard; George Lau; Victor Ponte; Michael Glascock

2006 "The history of prehispanic obsidian procurement in highland Ancash". En 
La complejidad social en la sierra de Ancash: ensayos sobre paisaje, economía y continuidades culturales. Milán Lima: Civiche raccolte d'arte applicata del Castello Sforzesco - Raccolte extraeuropee - Punku centro.

Caldas, Julio

1993 "Geología de los cuadrángulos de Huambo y Orcopampa, hojas 32-r; 31-r”. En Instituto Geológico Minero y Metalúrgico del Perú: Boletín 46, serie A: Carta Geológica Nacional.

Collins, Michael B

2002 Clovis blade technology. University of Texas Press.

Cooper, Judith R

2006 "A possible Clovis-age quartzite workshop (5GN149) in Gunnison Country, Colorado". En Current Research in the Pleistocene, 2006, 23: 85-88

Chauchat, Claude

1972 "Ensayo de tipología lítica del Precerámico peruano. En Revista del Museo Nacional, tomo XXVIII. Lima, pp. 125-132.

1982 "Le paijanien du desert de Cupisnique. Recherches Sur l'Occupation préhistorique de la Côte Nord du Pérou au Début de l'Holocène". Tesis Doctoral. Thèse de Doctorat d'État ès Sciences no . 745 Presentée à l'Université de Bourdeaux I por Obtenir le Grade de Docteur ès Sciences.

Goodyear, Albert C.

2003 "Evidence for Pre-Clovis sites in the eastern United State". En Paleoamerican origins: beyond Clovis. A Peopling of the Americas Publication. pp. 103-112.

Inizan, Marie-Louise; Michèle Reduron-Ballinger; Hélène Roche; Jacques Tixier

1995 Technologie de la pierre taillée. Tome 4. publié avec le concours du centre $\mathrm{Na}$ cional de la Recherche Scientifique et de l'Université de Paris X Nanterre.

Jennings, Justin; Michael Glascock

2002 "Description and method of exploration of The Alca obsidian source, Peru". En Latin American Antiquity, Vol. 13, №. 1 (Mar., 2002), pp. 107-118.
Klink, Cynthia; Mark Aldenderfer

2005 "A projectile point chronology for the South-Central andean highlands". En Advances in Titicaca basin archeology. Edited by C. Stanish University of California; Santa Barbara.

Lavallée, Danièle; Michèle Julien; Jane Wheeler; Claudine Karlin

1995 Telarmachay. Cazadores y pastores prehistóricos de los Andes. Tomo I. Instituto Francés de Estudios Andinos.

León Canales, Elmo

2007 Orígenes humanos en los Andes del Perú. Universidad de San Martín de Porres. Escuela Profesional de Turismo y Hoteleria.

Lynch, Thomas

1980 Guitarrero cave. Early man in the Andes. Studies in Archaeology. Academia Press. New York.

Merino, José

1994 Tipología lítica. Munibe (AntropologíaArkeologia). Suplemento no 9. Sociedad de Ciencias Aranzadi.

Neira, Máximo

1966 Prehistoria de Arequipa. Escuela tipográfica Salesiana. Arequipa-Perú.

Neira, Máximo; Guillermo Galdos; Alejandro Malaga; Eusebio Quiroz; Juan Carpio

1990 Historia General de Arequipa. Fundación M.J. Bustamante de La Fuente.

Pelegrin, Jacques

1995 Technologie lithique: Le châtelperronien de Roc-de-Combe (Lot) y de La Côte (Dordogne). Cahiers du Quaternaire № 20. CNRS Éditions. Paris.

Piel-Desruisseaux, Jean-Luc

1989 Instrumental prehistórico: forma, fabricación, utilización. Versión española de Valentín Villaverde Bonilla. Masson, S.A.

Ravines, Rogger

1967 "El Abrigo Caru y sus relaciones culturales con otros sitios tempranos del sur del Perú”. En Ñaupa Pacha 5. Berkeley, California, 1967: 39-57.

1971 "Toquepala: estratigrafía y secuencia". Tesis para optar el grado académico de doctor en la especialidad de Antropolo- 
gía. Lima 1971. Universidad Nacional Mayor de San Marcos. Programa Académico de Ciencias Sociales.

1972 "Secuencia y cambios en los artefactos líticos del sur del Perú". En Revista del Museo Nacional, tomo XXXVIII. LimaPerú.

2008 "Tipología lítica: puntas de proyectil del Perú". En Boletín de Lima. Revista Científica Cultural. Órgano de la Asociación Cultural Boletín de Lima A.C. Vol. XXX, №153, año 30, 2008.

Sandweiss, Daniel; Heather McInnis; Richard Burger; Asunción Cano; Bernardino Ojeda; Rolando Paredes; María del Carmen Sandweis; Michael Glascock

1998 "Quebrada Jaguay: early south american maritime adaptations". En Science, New Series, Vol. 281, № 5384 (sep. 18, 1998), 1830-1832.

Schroeder, Gerhard

1957 "Hallazgos de artefactos de piedra en el Perú y los problemas del poblamiento de América". En Revista del Museo Nacional, XXVI. pp. 290-294. Lima.

Sonneville-Bordes y Bezillon

1954 "Lexique typologique du Paleolithique Superior". En Bulletin Société Préhistoire Française. Vol. 51, pp.327-335.

Stanish, Charles; Ricahrd Burger; Lisa Cipolla; Michael Glascock; Esteban Quelima

2002 "Evidence for early long-distance obsidiana exchange and watercraft use from the southern lake Titicaca basin of Bolivia and Perú". En Latin American Antiquity, Vol. 13, №.4 (Dec., 2002), pp. 444-454.
Stiglich, Germán

1922 Diccionario geográfico del Perú. Por Germán Stiglich, Capitán de Fragata de la Armada del Perú, Vocal de la Sociedad Geográfica y de la Comisión de Demarcación Territorial, Condecorado con la Cruz Española del Mérito Naval de 3ạ clase. Obra premiada con medallas de oro por las municipalidades de Lima y Callao en e Centenario. Lima. 1922.

Tripcevich, Nicholas

2007 "Quarries, caravans, and routes to complexity: prehispanic obsidian in the South-Central Andes". Ph.D. dissertation, UC Santa Barbara, anthropology.

2009 "Exotic, goods, Chivay obsidian, and sociopolitical change in the south-central Andes". En Trade and Exchange: Archaeological Studies from History and Prehistory.

Tripcevich, Nicholas; Jesús Yépez

2009 La fuente de obsidiana Chivay y su posición en los Andes sur centrales. University of California, Berkeley.

Tripcevich, Nicholas; Daniel Contreras

2011 "Quarrying evidence at the Quispisisa obsidian source, Arequipa, Perú". En Latin American Antiquity, 22 (1), 2011, pp. 121-136. 